NIST GCR 21-030

\title{
Supporting Women and Under- Represented Minorities in the Sciences: Implementing Equitable Approaches to Organizational Change
}

\author{
Maya Noviski \\ University of Oregon
}

This publication is available free of charge from:

https://doi.org/10.6028/NIST.GCR.21-030 
NIST GCR 21-030

\title{
Supporting Women and Under- Represented Minorities in the Sciences: Implementing Equitable Approaches to Organizational Change
}

\author{
Prepared for \\ U.S. Department of Commerce \\ National Institute of Standards and Technology \\ Gaithersburg, MD 20899
}

By

Maya Noviski

COACh

University of Oregon

This publication is available free of charge from:

https://doi.org/10.6028/NIST.GCR.21-030

April 2021

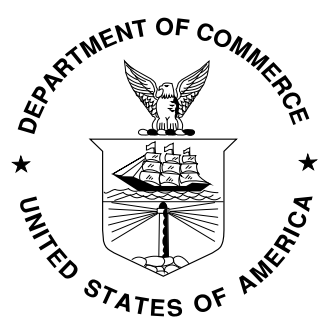

U.S. Department of Commerce

Gina M. Raimondo, Secretary

National Institute of Standards and Technology James K. Olthoff, Performing the Non-Exclusive Functions and Duties of the Under Secretary of Commerce for Standards and Technology \& Director, National Institute of Standards and Technology 


\section{Disclaimer}

This publication was produced as part of contract 1333ND19PNB670633 with the National Institute of Standards and Technology. The contents of this publication do not necessarily reflect the views or policies of the National Institute of Standards and Technology or the US Government. 


\title{
Supporting Women and Under-Represented Minorities in the Sciences: Implementing
} Equitable Approaches to Organizational Change

\author{
Maya Noviski, \\ Master of Public Administration at the University of Oregon
}

April 1, 2021

\begin{abstract}
This comprehensive literature review on equity within organizations and organizational change was submitted as a part a study designed to examine causes of inequity in promotions at National Institute of Science and Technology. The Final Report, "NIST: Needed Improvements in Standards and Transparency for Staff Promotion" can be found here: NIST GCR 21-029 https://doi.org/10.6028/NIST.GCR.21-029

Separated into five main sections, this review of scholarly and policy-related literature helped informed the study conducted by $\mathrm{COACh}$, a grassroots organization based out of the University of Oregon with a mission to increase the number and success of women and underrepresented groups in science and engineering. An accompanying annotated bibliography, found under Appendix A, provides an overview of the sources included in this body of work.
\end{abstract}

Keywords: STEM; Equity; Women; Minorities; Organizational Change; Organizational Culture 


\section{Table of Contents}

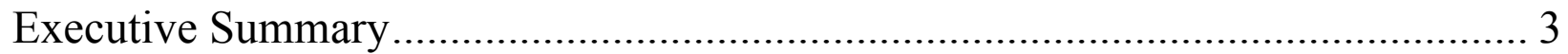

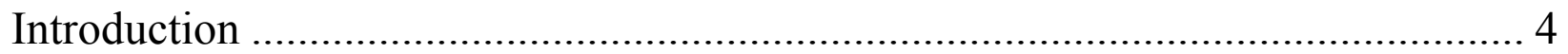

Organizational structure, culture, and behavior.................................................... 5

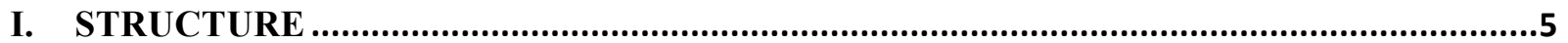

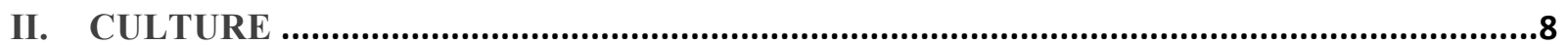

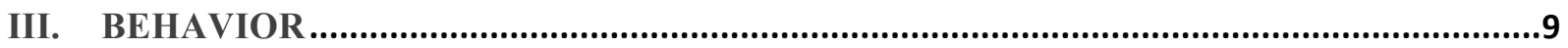

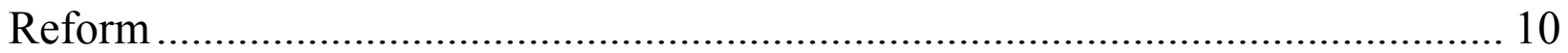

I. COMMITMENT FROM LEADERSHIP....................................................................12

II. HIRING AND PROMOTION OF DIVERSE STAFF ........................................................12

III. DIVERSITY MANAGEMENT TEAMS \& ORGANIZATIONAL CHANGE AGENTS ...13

IV. NETWORK GROUPS AND MENTORING OPPORTUNITIES .......................................15

V. INTERDEPENDENCE, PARTICIPATORY DECISION MAKING, AND

HIERARCHICAL STRUCTURES.............................................................................................16

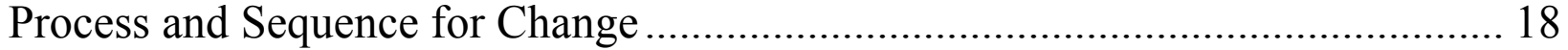

I. 5 STEP APPROACH .................................................................................................

II. SHIFTING ORGANIZATIONAL CULTURE ..............................................................19

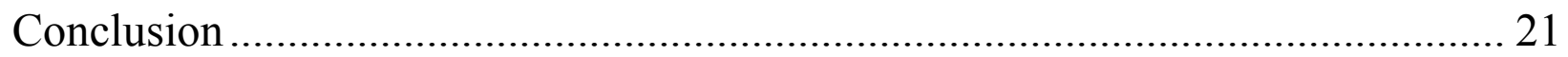

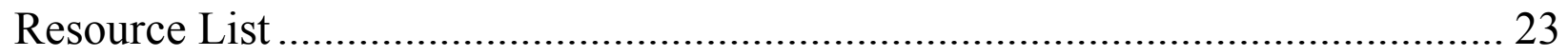

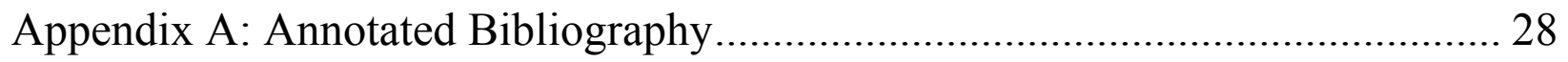

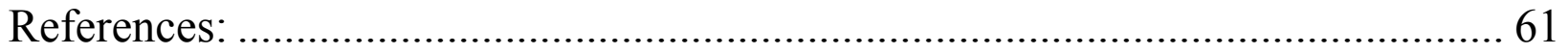




\section{Executive Summary}

The continued underrepresentation of women and minorities in science, technology, engineering, and math (STEM), has concerned researchers, scientists, and the federal government alike. Although $50 \%$ of the total work force, women make up less than one-third of all workers employed in STEM. African Americans and Hispanics, who make up 27\% of the total population, comprise only $16 \%$ of all STEM employees. While many theories have been put forth to explain the relative lack of women and underrepresented minorities (URM) in the STEM fields, this review points to underlying organizational structural, cultural, and behavioral variables that contribute to the leaky pipeline and reinforce barriers that prevent these marginalized groups from succeeding. Drawing from a wide breadth of literature and research from many fields including organizational management, public administration, psychology, sociology, and STEM, this review offers insight into significant and effective strategies for increasing diversity that have proven successful in many different sectors. By combining information from various fields, suggestions for organizational structural, cultural, and behavioral reform can be extrapolated to STEM workplaces where the literature regarding diversity and inclusion is still nascent.

It is appropriate and salient to note that any changes aimed at helping women and URM succeed will effectively benefit all workers, as systems that prevent certain groups from prospering negatively affect the entire population. Additionally, increasing diversity is not only associated with innovation, creativity, and competitiveness, but heterogeneous groups must work harder both cognitively and socially, which may lead to better outcomes. By committing to analyzing the ways in which certain organizational elements may prevent the inclusion, retention, and persistence of women and URM, real change may follow. 


\section{Introduction}

The underrepresentation of women and minorities in STEM has been the focus of scientific researchers, educators, employers, and governmental institutions alike. Since the 1970s, federal policies and funding opportunities have attempted to bridge the persistent gender and racial imbalances by focusing on ways to attract and retain women and underrepresented minorities (URM) in STEM fields ${ }^{1}$. However, these initiatives have fallen short of achieving lasting and meaningful change. For example, as of 2016, data show that African Americans and Hispanics make up about $27 \%$ of the overall US workforce but only comprise about $16 \%$ of STEM employees ${ }^{2}$. Additionally, it has been documented that "the percent of Black and Hispanic men who declare STEM majors upon college entrance is actually close in size to that of White men [...] likewise, Black women declare STEM majors at rates not significantly different than those of Black men. Instead, the rate of attrition from STEM majors within the first two years of college appears to be significantly higher among African Americans, Hispanic women, and White women than it is among White men and Asian men"3. It becomes clear, then, that it is not for disinterest that the numbers of URM in the STEM workforce are so low. Rather, this pattern appears to suggest lasting systemic barriers that have been left unhampered despite government interventions.

Similarly, the data for women in science support the notion that there are still obstacles preventing women from entering and succeeding in STEM fields. According to the National Science Foundation, in 2017, women were $29 \%$ of all workers employed in science and engineering ${ }^{4}$. The largest gender disparities persist among engineers where women make up only $16 \%$ of the workforce, followed by computer and mathematical scientists $(27 \%)$ and physical scientists $(29 \%)$. In academia, the numbers are equally low with women comprising less than one-quarter of faculty in computer and information sciences, math, the physical sciences, and engineering departments ${ }^{5}$. This continuing lack of diversity in STEM fields not only differs from progress made in other fields since the 1960s but could result in serious consequences for a sector that is seen as a pivotal pillar of the country's economy and security ${ }^{1}$.

Furthermore, the benefits of a diverse workforce are widespread. Research indicates that diverse perspectives are associated with innovation, creativity, and competitiveness. Seeing as heterogeneous teams must work harder both cognitively and socially, better outcomes may follow ${ }^{6}$. For example, a study analyzing groupthink among fraternity and sorority members found that including an outside member doubled the chances of teams solving puzzles that were presented to them ${ }^{6}$. Researchers concluded that the discomfort and unfamiliarity inherent with difference may lead to deep thinking and creativity. Hill et. al. (2010) ${ }^{5}$ also note that including more members in the development of "scientific and technological products, services, and solutions" will be more likely to "represent all users," and when women or URM are "not involved in the design of these products, needs and desires unique to women may be overlooked". These findings suggest that it is important, for greater scientific advancement, to understand the ways in which organizations can support the success and inclusion of women and URM employees. 
This support appears to be important at all points within female employees' careers to help to ensure that women remain in the field. The term "leaky pipeline," which is used widely in the sciences, describes the attrition of women in different career transition points ${ }^{7}$. Researchers have found "the academic system is losing women at a higher rate at every stage of their careers" academic science"9. The extant literature on this subject posits discrimination, isolation, and lack of mentoring, among other factors, as contributing reasons for the leaks ${ }^{10}$. Although the term, "leaky pipeline," has mostly been used to describe the attrition of women from the workplace, it is possible that factors contributing to the underrepresentation of both women and URM may overlap. Thus, responses designed to address gender disparities have the potential to affect people of color, as well ${ }^{11}$. The forces preventing women and URM from advancing and succeeding in STEM fields, along with suggestions and best practices for creating a more inclusive and welcoming workplace, will be further explored below.

\section{Organizational structure, culture, and behavior}

In order to increase the representation of women and URM scientists in STEM fields and in leadership positions, it is helpful to consider the influence of organizational structure, culture, and behavior on the retention and inclusion of these groups. It is important to note that while the workplace may appear to be meritocratic, several authors have suggested that this view may be more mythical than real, which may slow progressive actions and reforms ${ }^{12}$. For example, according to the Pew Research Center $(2018)^{2}$, "roughly six-in-ten Blacks (57\%) working in a STEM job say their workplace pays too little attention to increasing racial and ethnic diversity. By comparison, just $15 \%$ of whites in this field say this". Similar disparities appear with gender diversity. For instance, in 2005 the then president of Harvard, Lawrence Summers, suggested that the scarcity of female scientists at elite universities reflected gender differences in intrinsic aptitude. Nancy Hopkins, an acclaimed scientist at the Salk Institute, disagreed with these comments, noting that they were not supported by data. She reflected that the comments were especially painful because scientists are supposed to be interested in the truth and scientific evidence ${ }^{9}$. Nevertheless, these ideas persist and affect the experiences of marginalized groups. Therefore, it is essential to consider and place these occurrences at the forefront of any diversity initiative. By analyzing each of these three organizational components - structure, culture, and behavior - a holistic plan can begin to be devised to support the success of women and URM in STEM.

\section{STRUCTURE}

Organizational structure refers to organizational policies and practices ${ }^{13}$. This can include procedures around hiring and promotion, managerial oversight and discretion, and resource allocation. While equally significant, it is reasonable to begin by dissecting issues around hiring and promotion in an effort to uncover barriers preventing women and URM scientists from being considered in the first place. 
The considerable literature on issues with hiring and promotion points to several trends that may disproportionately affect women and URM in damaging ways. It has been noted that "most Blacks in STEM positions consider major underlying reasons for the underrepresentation of Blacks and Hispanics in science, technology, engineering and math occupations [including] discrimination in recruitment and promotions". Additionally, "among STEM workers, more say that whites are usually treated fairly in both the hiring and promotion processes in their own workplace than say the same for Asian Americans, Hispanics and Blacks in each of these situations" ${ }^{\prime 2}$. In academia, it is possible that these experiences could be attributed to the typical faculty search processes where some have suggested that search committees are often not diverse, lack expertise in hiring and recruiting strategies, and are prone to bias. This affects the applications reviewed and ultimately the composition of the shortlist $\mathrm{t}^{14}$.

Researchers have made similar conclusions regarding gender disparities. A report studying the likelihood of women being hired or promoted into managerial positions found that if there is a large presence of male recruiters, social similarity may influence a recruiter's level of comfort when introducing male candidates for organizational approval ${ }^{15}$. This supports the longstanding and highly regarded research that "has repeatedly demonstrated sex bias in employee selection processes with male applicants generally recommended for hire and seen as more likely to succeed than female applicants with the identical credentials when jobs are male in sex-type" ${ }^{\prime \prime}$. It is also important to note that when a woman is being considered for a position or promotion, her past accomplishments carry more weight than a male counterpart whose future potential has more clout ${ }^{17}$. This can be related to the common practice of relying on bibliometric parameters as a means for defining a researcher's success ${ }^{18}$. However, with longstanding biases in the peer review process that make it so that female post-doc applicants must publish and produce more than their male peers in order to be scored similarly, it becomes clear that emphasizing the h-index is flawed. This issue may be more acute in the physical sciences where blinded peer reviews are not common practice. Furthermore, Heilman $(2001)^{16}$ points out that women's work is often judged as poorer quality even if it is indistinguishable from her male counterpart's. This may lead to fewer publications and lower bibliometric scores.

In addition to the barriers women face in the academy, there is a considerable amount of research highlighting the challenges women face in rising to higher level positions in other organizational workplaces. Studies have suggested that the common organizational trend of looking to external candidates to fill senior positions rather than promoting from within can have severe repercussions for women who "tend to be concentrated in lower and middle-level positions, with men dominating more senior-level positions" ${ }^{15}$. This reliance on hiring rather than promoting for higher level positions contributes to the "glass ceiling," a term used to describe the barriers many women face in their careers preventing them from reaching senior level or leadership positions ${ }^{16,17}$. Clearly, many interrelated factors may influence the probability of ascension for women or URMs in an organization. Focusing on ways to make the hiring and promotion process more equitable will improve the structure of the organization as whole. 
While analyzing hiring and promotion practices is critical to assessing organizational structure, policies influencing the amount of discretion managers have on the success and ascent of an employee is important to highlight. For example, managerial influence on evaluations and access to certain resources may prove harmful if policies and formal structures are not implemented that reduce bias and differential treatment. In line with the research on diversity and perceptions of equity in the workplace, it is noted that "one of the main things Blacks complained about $[\ldots]$ was the withholding of information by white supervisors ${ }^{19}$. Similarly, Elvira and Town $(2001)^{20}$ found that "interpretations of performance depend on the races of supervisor and subordinate." They concluded that "if differential ratings lead to lower promotions for Black employees, Blacks will be less likely to rise into managerial positions" 20 .

The interpretations of performance transcend racial differences and are affected by gender, as well. Research indicates that gender stereotypes affect both the social and professional ways in which managers and employees are regarded ${ }^{16,21}$. As Heilman (2001) describes, when considering what makes a good manager, attributes that are stereotypically male, such as independence and decisiveness, predominate the descriptions of successful supervisors. These views produce a perceived "lack of fit" ${ }^{16}$ between women and supervisory positions affecting women's ascent within the organization. It has also been noted that when women negotiate for higher pay or a higher-level position, they face the risk of losing "social and economic capital, as in not being liked at work nor being hired or promoted" ${ }^{21}$. This is attributed to not acting in a traditionally female manner or breaking gender norms, which can be frowned upon and met with derision. Therefore, women may choose to remain submissive out of fear of reprisal.

Additionally, Chang and Milkman ${ }^{22}$ note that women face pressure to spend more time than men helping others and working on tasks that will not have high returns for their careers. If they fail to do as expected, they receive more backlash than men. It is intelligible, then, that the power managers are able to wield in the absence of clear, standard policies may negatively impact women and URM. It has been documented that "the lack of information and clarity regarding [women's] work goals, objectives, and responsibilities" ${ }^{23}$ is a major factor in women's dissatisfaction and detachment from the workplace and can result in higher rates of attrition.

The lack of standard practice and expectations can extend to resource allocation, as well. ${ }^{24}$ note that historically, female faculty have had less access to research resources. This is corroborated by a study that was conducted by MIT analyzing the status of women faculty in different departments in its School of Science which showed that tenured women faculty felt more marginalized and isolated. Marginalization was often accompanied by differences in "salary, space, awards, [...] and resources". ${ }^{25}$ Female scientists at the highly esteemed Salk Institute also mentioned gender disparities in resource allocation noting how the all-woman regulatory biology department was relegated to the basement and the senior female faculty had labs smaller than their male counterparts ${ }^{9}$. Additionally, women in senior positions were given the majority of the smallest spaces on the campus even after raising more money per employee than their male peers. This practice, while possibly unintentional, sends a clear message that 
women are devalued. Moreover, the unequal distribution of resources hinders female success while benefitting male scientists and supporting the disparities in recognized accomplishments.

\section{CULTURE}

The culture of an organization can be thought of as the "basic assumptions, values, beliefs, and ideologies that define an organization's view of itself, its effectiveness, and its environment" ${ }^{\prime 3}$. For women and URM, workplace culture can be a major factor in how accepted, supported, and included these populations feel. In STEM especially, there have been longstanding beliefs that reinforce exclusion and perpetuate gender and racial stereotypes, adversely impacting marginalized groups. For example, it has been noted that within engineering, there is a widespread belief that women are unable to execute technical tasks and should stick to the social aspects of the field. This is substantiated by Cech's ${ }^{26}$ findings that if women spend more than $10 \%$ of their time on research or design work, which is seen as technical work, they may face pay penalties; whereas if the same amount of time is spent on social activities, the penalties are non-existent. Furthermore, Cech highlights that "women and minorities may be encouraged to enter lesser paying subfields that are seen as most "appropriate" or the best "fit" for them, according to ideologies about professional work". This cultural bias may lead to inequalities in the workforce including wage disparities along gender lines.

Apart from Cech's research, anecdotally, female engineers have expressed that "older male engineers certainly think that females shouldn't be engineers, or that it's 'cute' when they are, like it's an amusing phase she's going through, instead of a career" ${ }^{23}$. Similarly, women have stated that "you either need to learn to be 'one of the guys' or blaze the trail yourself", These assumptions and beliefs are not intrinsic to engineering alone. In fact, women have expressed that "there is little to no respect for women in male-dominated fields" 23 , which, save for the social sciences, include most of the occupations in STEM ${ }^{2}$. African-Americans have also reported that "it is believed that Black people as a whole are lazy and unqualified" ${ }^{2}$ which may lead to differential treatment.

These unsupportive environments are so ubiquitous that they are referred to as the "chilly climate." Several conditions that result in chilly climate include "negative interpersonal relations, subtle and overt denigration of skills, attribution of attainment to affirmative action policies, avoidance of eye contact, favoritism toward male and majority students, sexual harassment, and, in the workplace, a dearth of opportunities to advance, failure to be recognized for contributions, and wage disparities" ${ }^{1}$. Unsurprisingly, chilly climates are known to provoke feelings of isolation and self-doubt. This is especially true for women and URM in STEM, where their numbers in leadership positions remain notoriously low, leaving these marginalized groups to contend with "gender-conservative men and structures" untoward environments can lead women and URM to reconsider pursuing a degree or occupation in STEM ${ }^{1}$. In order for true change to occur, Coe et. al. ${ }^{12}$ posit that "climate and culture must be addressed together because efforts to build a good climate will be unsuccessful if the policies conflict with the beliefs, assumptions, and values of an organization". Hence, by analyzing both 
of these forces together, organizations may be able to expose some of the more insidious ways the workplace environment proves unwelcoming for women and URM.

\section{BEHAVIOR}

Organizational behavior can be described as the "behaviors, attitudes, and perceptions within and between individuals, and within and between work groups"13. While some behaviors may be unintentional or even subconscious, others may be aggressive and careless. Although occurrences of explicit bias may be less prevalent, observers suggest that implicit or unconscious bias continues to permeate STEM fields and contributes to gender disparities in STEM. Hill et. al. ${ }^{5}$ note that "implicit biases against women in science may prevent girls and women from pursuing science from the beginning, play a role in evaluations of girls' and women's course work in STEM subjects, influence a parent's decisions to encourage or discourage their daughters from pursuing science and engineering careers, and influence employer's hiring decisions and evaluations of female employees".

Similar to the way in which women and minorities experience differential treatment by managers in the absence of formal policy and structure, so too are they more susceptible to implicit bias in the aforementioned situations. This notion is supported by Heilman who notes that "the more inference is required to draw implications from performance information, the more likely bias will enter into evaluative judgements" ${ }^{\prime 16}$. This is supported by Corell et. al. ${ }^{28}$ who note that in the absence of a formalized, well-defined and easy to use performance evaluation, negative biases can affect women and people of color at higher rates, which may lead to worse professional outcomes. They argue that if an evaluation process is ambiguous, managers will rely on "widely shared gender beliefs [which may] subtly frame their observations, interpretations, and valuations of employee behavior",

Unmanufactured examples of biased judgments when inference was required occurred in a study where participants were asked to rate the competence of female and male employees in the presence and absence of information regarding the individual's prior success. Results showed if past accomplishments were explicitly stated, participants rated both female and male employees as equally competent; however, if that data were not presented, women were rated as "significantly less competent than the man".

Unfortunately, even presenting past successes may not preclude a woman from being subjected to unwarranted biases that prevent her from prospering. Bosak et. al. ${ }^{29}$ confirmed Hill et. Al.'s finding by expressing that "gender stereotypes influence perceivers and can lead to discrimination in hiring and promotion decisions." This is especially true when managers evaluate employees individually rather than as part of a team. A study by the Harvard Kennedy School found that when managers thought about employees in groups, it was easier to compare individuals by performance ${ }^{30}$. Conversely, when employees were thought of as autonomous, managers "fell back on gendered heuristics [resulting in] poorer hiring decisions and more gendered choices" ${ }^{\prime 30}$. Gender heuristics also influence expectations around how women should or 
ought to behave. If a woman is seen as successful in a role that defies "gender stereotypic norms," such as a manager or boss, she may be penalized both socially and professionally ${ }^{31}$. This is supported by Schneider ${ }^{21}$ who describes the way in which biases about how women should behave can lead to backlash when women are seen as assertive or confident and women in leadership are often forced to decide between being 'likeable or competent,' which can affect a woman's decision to advocate or negotiate for a promotion at the outset.

In workplace environments where implicit bias is left unchecked and women are consistently subjected to microaggressions, research suggests that the probability of attrition is much greater.

Holvino et. al. ${ }^{13}$ describes microaggressions, or microinequities, as behaviors that "support exclusion and differential treatment towards some people in practices such as restricted information and feedback from supervisors and co-workers, inequitable delegations of tasks, and exclusion from informal social networks and peer support". It has been reported that women "are more than twice as likely [than men] to be asked to prove their competence, over three times more likely to be mistaken for someone more junior, and about twice as likely to be subjected to demeaning or disrespectful remarks" 17 . These behaviors, along with the low numbers of women in STEM, can lead women and URM to feel isolated and tokenized.

The effects of tokenization, as Kanter's theory of tokenism suggests, can be abated only when the representation of a minority group reaches a "critical mass," which is generally thought to be over $15 \%^{32}$. In fields such as engineering where women only make up $16 \%$ of the workforce or with African Americans and Hispanic workers comprising an identical percentage of STEM professionals overall, it is no wonder that certain STEM environments may feel unwelcoming to these marginalized groups. This may be especially true for women of color. McKinsey and Company ${ }^{17}$ report that Black women often find themselves as the only woman and the only person of color in the room.

Acknowledging and working to eliminate implicit biases and microaggressions in the workplace not only benefits women and URM, but men as well, who have reported backlash when acting in gender atypical ways. Bosak et. al. ${ }^{29}$ found that men who advocate for others, rather than focusing on themselves and portraying characteristically masculine traits, risk recommendations for dismissal. Similarly, research has shown that men who are perceived as less self-promoting and more egalitarian are evaluated by both men and women as less competent $^{33}$. Consequently, in order to promote equality and equity for all and create a work environment that benefits each employee, diversity and change initiatives must focus on reforming harmful organizational structural, cultural, and behavioral tendencies that prevent employees from reaching their maximum potential.

\section{Reform}

In the previous section, common organizational structural, cultural, and behavioral issues that hinder the success and inclusion of women and URM in STEM were outlined and discussed in order to inform ways to target diversity initiatives that result in sustainable and meaningful 
change. While identifying the problems endemic in STEM and workplace environments is the first step, transforming organizational practices and norms is a long-term commitment that must be well thought out and supported by organizational leaders. In Creating and Sustaining Diversity and Inclusion in Organizations: Strategies and Approaches, Holvino et. al. ${ }^{13}$ outline common mistakes that organizations make while trying to reform. These include failing to relate diversity to the organizational mission, isolating the effort in one department or under one person, not differentiating between good intentions and the impact of specific institutional actions that go against diversity, and not paying attention to the impact of resistant people in important positions.

Apart from these shortcomings, declining to emphasize the inclusion of women and URM in any diversity initiative may be detrimental to its success. Rather than just focusing on increasing the numbers of minority or women employees, inclusive environments are characterized by "a collective commitment to integrating diverse cultural identities as a source of insight and skill" ". This is markedly different from organizations which focus on "increasing diverse representation but continue to expect nontraditional employees to assimilate to dominant norms" ${ }^{34}$. Smith-Doerr et. al. ${ }^{32}$ further posit that "representational diversity, where organizations have workforces that match the pool of degree recipients in relevant fields, is a necessary but not sufficient condition for diversity to yield benefits. Full integration of minority scientists (i.e., including women and people of color) in an interaction context that allows for more level information exchange, unimpeded by the asymmetrical power relationships that are common across many scientific organizations, is when the full potential for diversity to have innovative outcomes is realized".

The researchers note that simply adding minority scientists to the workplace will be insufficient if the organization is not structured for those scientists to be valued and heard. Therefore, it is important that scientists have opportunities to get to know each other more personally and work together across roles, levels, and demographic boundaries to solve problems and engage in participative decision making ${ }^{34}$. This notion is confirmed by Johnson \& Smith $^{33}$ who note that "the more positive interactions men have with women in professional settings, the less prejudice and exclusion they tend to demonstrate." Therefore, the success of any diversity initiative aiming at true equity and power sharing must necessarily consider inclusion, a foundational element of lasting reform ${ }^{13}$.

Aside from integrating inclusive measures into any and every diversity initiative, Holvino et. al. ${ }^{13}$ discuss several other important organizational interventions that facilitate diversity. These include personal involvement of the top management and organizational leaders, the recruitment of diverse staff in managerial and non-managerial positions, internal advocacy and change agent groups, and support network and internal affiliation groups. The breadth of these interventions confirms the notion that diversity efforts must cut across every organizational level to counter the gap that often emerges between "formally stated goals of diversity initiatives and the values actually adopted during day-to-day organizational life" ${ }^{\text {"35 }}$. These interventions, along with several others, will be discussed in depth followed by suggestions for implementing change. 


\section{COMMITMENT FROM LEADERSHIP}

The abundance of literature on organizational change initiatives consistently points to the importance of engaging top management and organizational leaders in any transformational effort. For example, Coe et.al. ${ }^{12}$ note that male leaders, and particularly those with power, privilege, and social capital, are essential to challenging beliefs around gender and ability. Similarly, Bilimoria et. al. ${ }^{7}$ write that leaders, influencers, policy makers, and male colleagues must listen to and believe women when they share their stories and experiences in order to effect change in science. Sturm ${ }^{36}$ argues that "institutionalization depends upon engaging institutional stakeholders with the power, incentives, and capacities to continually question and revise policy, practice, and culture over the long run". This was seen in a study analyzing two organizations that had very different approaches to increasing diversity and changing their organizational

environment $^{37}$. The researchers found that within the more efficacious organization, the CEO was committed to analyzing and reforming the organization, and his role was pivotal in fostering change ${ }^{37}$.

One way to engage top leaders is through planned mediations. During a workshop aimed at addressing issues related to negative gender climate, chemistry department heads from across the country were invited to attend and learn about underlying reasons for the underrepresentation of women faculty and the barriers to their progress in academic chemistry departments ${ }^{38}$. By measuring department heads' attitudes both pre- and post-workshop, researchers found that these planned interventions impacted the way leaders thought about women's ability to succeed in the field. This is significant because as Stockard et. al. ${ }^{38}$ reported, "leadership of a department was a significant influence on women faculty members' job satisfaction, perceived influence, and reports of productivity, independent of their individual experiences of sexual harassment and gender discrimination [...] given their structural location between faculty and higher administration, as well as their ability to influence discussions and actions within a department, department heads are seen as crucial players in any attempt to develop change".

In another review analyzing institutional change, $\mathrm{Sturm}^{36}$ discusses how the University of Michigan held campus wide initiatives with task forces producing policy change, conducting chair training, and supporting data-based workshops for various disciplines. Furthermore, the university, with funds from a National Science Foundation grant, collaborated with advocates, experts, and governmental figures to help with leadership development ${ }^{36}$. In sum, it is evident that any successful diversity initiative must first engage and involve powerful stakeholders. Through workshops, trainings, and cross-institutional collaboration, top leaders can be informed and supported as they move to implement organizational changes.

\section{HIRING AND PROMOTION OF DIVERSE STAFF}

Contingent upon the support from leadership and organizational stakeholders, recruiting women and URM scientists becomes the next focus. As noted previously, implicit bias is 
insidious and commonplace, and often influences hiring and promotion. Therefore, it is important to recognize the subjectivity in the valuation process in order to create systems that protect against bias $^{18}$. Sturm ${ }^{11}$ posits that seeing diversity as a group phenomenon could encourage hiring staff to consider new hires as a group instead of individually, possibly mitigating some of the effects of gender heuristics on female candidates.

Gender heuristics may also be allayed by ensuring that search and hiring committees are diverse while providing appropriate training to build awareness around biases and fair hiring practices $^{14}$. As noted previously, these committees are often homogeneous, possibly leading to social similarity affecting which candidates are perceived to be the best $\mathrm{fit}^{15}$; this may result in poor hiring decisions because diverse teams are known to produce better outcomes ${ }^{6}$. In addition, Bilimoria \& Buch $^{14}$ urge organizations to switch to "proactive models of recruitment and aggressively pursue talented and diverse applicants rather than waiting for them to apply". In their work, Gilbert \& Ivancevich ${ }^{37}$ highlight how members of one organization's hiring team went to conferences for minority workers and attended career fairs at universities with high numbers of minority students in order to "proactively" 14 seek diverse employees.

Apart from focusing on the hiring teams as catalysts for increasing diversity, experts stress the importance of formalizing the system and criteria for decision-making in an effort to shield decisions from being too heavily influenced by the biases and stereotypes of the decision maker $^{39}$. Included in this is increased transparency around salaries and benefits ${ }^{21}$, and promotional opportunities through job posting systems, which have been shown to make female and URM employees more aware of such openings ${ }^{40}$. Increased transparency and job satisfaction were shown to have a positive relationship in ${ }^{41}$ research as well, where the two studied how information disclosure may affect professors' job attitudes. They conclude that transparency, "specifically, the department's openness about structures, processes, and resources - is not only a relevant factor for how satisfied professors are with their working conditions but may also result in a reduction of professors' intentions to leave". While their research focuses on faculty in academe, it is possible that their findings may be extrapolated to other areas, as well.

Once the decision-making system is formalized, it is important for organizations to clearly communicate the standards for performance and qualifications for promotions, while creating an open environment where supervisors can honestly communicate with their employees about promotional decisions ${ }^{42}$. Through formalization, clarity, and transparency, the effects of implicit bias on hiring and promotion decisions may begin to be assuaged.

\section{DIVERSITY MANAGEMENT TEAMS \& ORGANIZATIONAL CHANGE AGENTS}

In order to help foster inclusion and maintain accountability, organizations may consider creating diversity management teams and identifying organizational change agents. It is common for many organizations to have one diversity manager responsible for overseeing an organization's affirmative action program and ensuring that the rules and regulations of any 
legislation are being followed ${ }^{43}$. More recently, however, organizations have begun creating diversity management teams, which are often made up of managers from different departments tasked with the responsibility of increasing the number of women and URM in higher level positions ${ }^{43}$. This may be done by analyzing gender gaps, recommending corrective action, and establishing systems for monitoring and accountability. Dobbin and $\mathrm{Kalev}^{43}$ find that executives view diversity managers and taskforces as being effective because of their ability to recognize certain problems and create solutions. Additionally, because the taskforces include managers from different departments, there is more widespread support for achieving diversity.

It is important to note that these taskforces have been found to be more successful at increasing diversity than training sessions and diversity performance evaluations for managers ${ }^{43}$. Kalev et. al. ${ }^{44}$ report that "strategies designed to change individuals are less effective than the conventional management solution" which include creating "structures that embed accountability, authority, and expertise (affirmative action plans, diversity committees and taskforces, diversity managers and departments) [which] are the most effective means of increasing the proportions of white women, black women, and black men". This notion is supported by Holvino et. al. ${ }^{13}$ who emphasize that training tends to focus on changing individual behavior rather than addressing systemic structural and cultural factors, thereby restricting change to that liminal level.

Similar to diversity management teams are organizational catalysts or change agents who are individuals that "leverage knowledge, ongoing strategic relationships, and accountability across systems ${ }^{\prime 36}$. These individuals, who have influence and credibility, are placed in positions where they can guide institutional reform. At the University of Michigan, organizational catalysts were at the center of the institution's change initiative and were given resources and legitimacy to help with implementation. Simultaneously, strategists aimed to reconfigure existing administrative positions to integrate gender and equity responsibilities.

However, the responsibilities of change agents need not fall on one person. Expanding on the idea of an organizational catalyst, Sturm ${ }^{36}$ posits that different people may adopt various roles and responsibilities, which creates participatory oversight by groups when evaluating the work of the office. However, it is important to understand that change agents must be ready to act as both mediaries and visionaries by answering questions and responding to resistance around change while coming up with astute resolutions to problems seen as critical to an organization's long-term success ${ }^{7}$. For example, organizational catalysts at the University of Michigan monitored gender concerns and ensured that "issues affecting women's participation [were put] on the agenda" $"$. Furthermore, organizational catalysts helped create opportunities for "women and men concerned about gender to meet, share their experiences, develop effective strategies, learn from mistakes, and take action to address issues of common concern". It is salient to underscore that these change agents were seen as one of the most important factors in the longevity of diversity reform ${ }^{36}$. The value of change agents is due in part to their knowledge of the organizational culture and subsequent proceedings. Consequently, these individuals are 
believed necessary to include in the process of increasing diversity and promoting organizational change.

Corell et. al. ${ }^{28}$ make similar conclusions about sponsors, who were shown to effectively help women advance and avoid backlash in corporate fields. Through a study analyzing managerial biases in employee performance reviews, Corell et. al. ${ }^{28}$ note that having a sponsor, or someone who advocates for women, "had the largest positive effect on rating for women [...] including increasing the odds of women receiving the highest rating most strongly associated with promotion".

\section{NETWORK GROUPS AND MENTORING OPPORTUNITIES}

In addition to roles and taskforces dedicated to ensuring accountability and raising awareness, creating space for network groups and mentoring opportunities has been found to increase feelings of inclusion and attachment to the workplace for women and URM. As described by Friedman \& Craig ${ }^{45}$, network groups are "established groups of employeesusually women or minorities - that get together for various activities". Network groups may be comprised of an array of contacts at different levels of the organization's hierarchy, so they are seen as an equitable response to helping women and URM access important social support, information, and leadership opportunities ${ }^{45,46}$. It is important to note that network groups do not form as a result of job dissatisfaction or employee perceptions that the organization is a substandard place to work. Rather, network groups tend to be founded upon shared group identity. Therefore, allowing these groups to prosper may lead prospective minority employees to feel more supported and comfortable joining the organization.

It becomes clear, then, that organizations aiding in the prosperity of network groups help provide a place where information and advice is shared, ${ }^{39}$, community is fostered, and mentoring relationships formed. Mentoring, which is explained in the literature as senior women or senior URM who, through a matching process, are paired with lower-level members of the same group for one-on-one meetings, has a number of benefits for marginalized groups. Some of these include providing instrumental psychosocial support and aiding in the career development of their protégés by providing access to information and resources ${ }^{47}$. The psychosocial function of mentoring has also been shown to positively impact retention rates of URM students in STEM and reduce women's feelings of marginalization in the workplace by providing a stronger sense of confidence and place ${ }^{5,45,48}$.

While it is clear that both network groups and mentoring programs provide information to those who are often excluded from the "old boys' network" and are therefore not privy to certain job or training opportunities ${ }^{39}$, network groups and mentoring can also increase women and URM employees' sense of inclusion and organizational embeddedness, which may result in lower attrition rates ${ }^{45}$. Additionally, it has been argued that the self-assuredness and connection 
to the workplace felt by minority employees, fostered through networking groups and mentoring relationships, can help marginalized groups advance to leadership. Furthermore, issues affecting women and URM may be brought to top managers, thus connecting those in higher positions with underrepresented employees ${ }^{45}$.

While the benefits of networking groups and mentoring relationships are strongly supported by the research, Chapman ${ }^{49}$ aims to deconstruct and expand upon the traditional mentoring model by positing six roles that different partners can adopt to expand the network that mentees can learn from and rely on. These roles include associate, advocate, connector, mentor, coach, and targeted training. Chapman encourages organizations to enlist partners who traverse "identity dimension, communities, and scholarly disciplines" and these partners provide different types of support. She describes Associates as mutual accountability partners who help mentees set goals and reevaluate work strategies. Advocates, or sponsors, use their power to help redirect opportunities to which the mentee may have been previously unaware. Connectors help connect mentees to influential people and access networks previously unapproachable. Mentors focus on overall career trajectory. Coaches identify strengths and weaknesses and provide advice on how to become a stronger employee through trainings, and training partners focus on specific skill building bringing the mentee to a necessary level of proficiency and procedural knowledge. Of course, critical to this process is the partner's acknowledgment of personal biases, assumptions, and stereotypes possibly affecting the advancement of a mentee ${ }^{49}$. Nevertheless, by gathering a coalition of people across an organization willing to help support and uplift women and URM, it is possible that feelings of inclusion may increase, and success more widely spread.

\section{INTERDEPENDENCE, PARTICIPATORY DECISION MAKING, AND HIERARCHICAL STRUCTURES}

Intergroup contact, which is the basis of Chapman's ${ }^{49}$ framework, is not only beneficial in mentoring relationships but is crucial for the success of women and URM throughout the entire organization. This notion was identified by Ibarra $^{46}$ who explained that "minorities with greater potential for advancement will develop a mix of same-race and cross race relationships". As it relates to inclusion, providing opportunities for employees in different working groups to collaborate together and forge professional relationships and friendships is especially important for minority employees who often feel performance pressures more keenly and can greatly benefit from intergroup contact ${ }^{50}$.

However, the benefits of cross-sector relationships are not confined to marginalized groups alone. By working to integrate differences across multiple identities in an effort to personalize employees from different backgrounds, the advantages of diversity will be realized and the organization as a whole will be rewarded. It is important to note that when attempting to bridge gaps and help employees relate to one another, minority groups may face resentment and backlash if it is not clear that everyone can benefit ${ }^{34}$. Therefore, it is imperative to create an understanding that intergroup contact is desirable for all. 
In addition to intergroup contact, another way to create an inclusive environment is by including employees in decision-making processes. One way to do this is by creating pathways for employees to share ideas for improvement within the organization ${ }^{37}$. In other words, empowering employees with authority, resources, information, and accountability as well as including employees in decision-making processes can foster a deeper commitment and attachment to the workplace ${ }^{34,37}$. Gilbert and Ivancevich examined change processes and outcomes in two organizations. They found that the organization that saw meaningful change brought together a team of cross-section managers who identified ways in which the organization could improve. Additionally, a team of cross-section employees met monthly to discuss ways the organization could progress and "through solicited comments and regular participation, employees shared ownership in determining policies at work" ${ }^{37}$. Not only does this create a sense of responsibility but it helps employees communicate which cultural changes that they would like to see take place.

Encouraging employees to take part in organizational processes is also discussed by Picciano ${ }^{51}$ who posits that organizations should consider shifting towards a culture of shared accountability rather than relying on individual performances. Picciano writes that, "rather than assign tasks based on an approved plan, leaders should invite team members to build the plan with them." By focusing on inclusivity, team members become more aware of how they contribute to the organization's shared vision. This collaborative process ensures commitment from employees and fosters an understanding of who is accountable for which tasks, and when. Picciano suggests that leaders clearly prioritize shared accountability from the beginning and outlines communication, cooperation, and collaboration as three key components to building this type of management system. This will allow organizations to improve project management and strategy execution while engaging employees and taking full advantage of their human resources potential.

The organizations that support this type of collaborative decision-making are typified as a network form, rather than a hierarchical one. A network form is a workplace that relies on interorganizational relationships, has a more open-ended tone, and values collective impact over individual ascent on the hierarchical ladder ${ }^{52}$. These environments, where cross-job communication and nonhierarchical structures predominate, have been shown to have positive effects on women's productivity and success ${ }^{52,53}$. Furthermore, organizations that focus on developing their human capital through fostering positive leadership practices, engaging employees, allowing knowledge accessibility, implementing workforce optimization practices and supporting organizational learning capacity, become more competitive ${ }^{54}$. FRM Dom \& Ahmad argue that human resource departments become crucial in this process as organizations look to grow and succeed.

While it may not be possible to completely reorient an organization's decision-making structure, incorporating elements of network forms such as creating opportunities for cross communication and participatory decision-making can lead to a more positive work environment for all employees. Although it is true that many traditional systems disproportionally exclude and 
do not support women and URM, it is salient to note that practices in which inequality and bias are perpetuated inevitably impact everyone negatively. Therefore, promoting a better functioning and successful organization in which harmful structural, cultural, and behavioral elements are mitigated will effectively reform the workplace for all.

\section{Process and Sequence for Change}

With several suggestions outlined above for creating a more inclusive and welcoming environment, it is important to outline how to approach implementing organizational change. As discussed above, without a steadfast plan, organizations may fail to achieve the ultimate goal of increasing diversity and supporting the success of women and URM. A highly influential fivestep approach that Holvino et. al. recommends is (1) preparing for the initiative, (2) assessing the needs related to diversity, (3) developing a vision, goals, and strategic plan, (4) implementing the interventions selected, and (5) monitoring and evaluating progress and results. While these steps may appear linear, Holvino et. al. stress that this is a cyclical process with the last steps informing the first. Additionally, they recommend leaving the plan open and flexible until data has been gathered and needs assessed so that initial decisions can be better informed. Below is an explanation of Holvino et. al.'s five-step approach with additional tools for shifting organizational culture.

\section{5 STEP APPROACH}

1. Preparation: In the first stage, organizations should look to securing leadership support and developing a plan of action. Important elements of this stage include communicating the intent of the initiative, allocating resources, assigning responsibilities, and framing initial tasks.

2. Assessment: Following the preparation, assessing the needs related to diversity comes next. This includes gathering data in the form of surveys, focus groups, and cultural audits, which are analyzed in order to develop appropriate recommendations based on the results.

3. Plan: The third stage includes developing a strategic plan that specifies goals, interventions, and sequence of activities. The importance of a well-crafted strategic plan should not be understated seeing how it guides a diversity initiative by "informing the organization about the importance and flow of the change effort, defining goals for management [...], providing a structure, clarity, and accountability for the initiative, [and] linking the change effort to the competitive advantage and gains that will be derived from the initiative". The strategic plan should also include a definition and vision for diversity and inclusion that is specific to the organization.

4. Implementation: Once the vision, definition, and action plan are solidified, organizations can move on to the implementation stage. There are several important elements to consider when beginning this phase including who will be involved, the types of interventions selected, the timeline and sequence of events, and at what hierarchical levels will these activities take place. Communication, credibility, and accountability are vital for the success of any strategic plan. Therefore, having a solid plan that involves visible leadership from the top and middle management and pathways for information sharing is crucial. 
5. Monitoring and Evaluating: The final stage involves monitoring, or ensuring that the plan is being accomplished, and evaluating, or determining the impact and results of the intervention. Holvino et. al. emphasize that "evaluation is one of the most neglected aspects in diversity initiatives and requires careful planning regarding the scope of the evaluation, the information that will be sought from the evaluation process, how and for whom information will be gathered, the use of the data, and to whom and how it will be fed back". In terms of monitoring, common methods of assessing progress include tracking representation, advancement, and retention of women and URM. Others include changes in individual attitudes and behavior, the impact of interventions on organizational culture, and the level of satisfaction of members of different groups in the organization. This can be done through program evaluations, climate surveys, or cultural audits. As expressed previously, simply hiring more women and URM will not necessarily result in a cultural shift or guarantee the success of a diversity initiative. Therefore, it is important to include ways to understand and add elements that will shift organizational culture when devising any diversity initiative.

\section{SHIFTING ORGANIZATIONAL CULTURE}

While it is clear that any successful diversity initiative must consider the steps outlined above, analyzing organizational culture is a significant step in creating meaningful change. As Cameron \& Quinn ${ }^{55}$ note, the most powerful factor and competitive advantage successful organizations have is their organizational culture. In their book, Diagnosing and Changing Organizational Culture: Based on the Competing Values Framework, they outline an approach for initiating cultural change. Key steps include (a) reaching a consensus regarding the current organizational culture and the preferred culture; (b) identifying a strategic plan; (c) celebrating small wins; (d) identifying metrics to maintain accountability; and (e) identifying a communication strategy. As discussed above, two ways to understand climate and culture are through surveys or audits. These methods are useful in narrowing the areas to focus change initiatives and helping leaders understand standing strengths and challenges ${ }^{7}$. This is especially important as researchers have noted that culture and climate must be aligned to improve outcomes for women and URM in STEM, and evaluating the current status of organizational climate can help promote positive advances ${ }^{56}$.

When designing climate surveys, there several types of questions that organizations can incorporate into their evaluations of workplace environment. Some research questions that help uncover the ways in which employees are feeling include, "Do all employees consider systems of performance appraisals, rewards and promotions to be fair and unbiased? Do all employees have access to important information that enables them to do their jobs and contribute? Do all employees have the ability to influence decision-making? Do all employees perceive that they have opportunities to acquire and develop new skills and advance their careers? Do all employees perceive that they have opportunities for formal and informal mentoring and coaching?" ${ }^{\prime 13}$. It is important to highlight that the analysis of these assessments is best conducted by a combination of internal change agents who have experience with the organizational culture and systems and external consultants who can bring an outsider's perspective. 
Equally important to remember is that while year-to-year assessments may not reveal any changes until the fourth or fifth year ${ }^{57}$, some indicators of a successful organizational shift as outlined in Holvino et. al. include:

1. People of diverse backgrounds working at all levels and departments of the organization;

2. Diversity as an explicit goal in recruitment strategies, equity in employment actions and systems;

3. Diversity objectives being set and met from the top to the bottom of the organization;

4. Diversity as an integral part of the organization's operating principles and values which are recognized as driving organizational behavior;

5. Managers are trained, assessed, and held accountable; and

6. The organization continually assesses and learns about the dynamics of diversity and its impact on the people and work of the organization.

In addition to climate and cultural surveys and audits, the Organizational Culture Assessment Instrument (OCAI) is useful in identifying areas in which cultural change must occur. As Cameron and Quinnon ${ }^{55}$ explain it, "the OCAI is designed to help identify an organization's current culture or the culture that exists today" and can help leaders diagnose an organization's cultural strength, type, and congruence. Conversely, identifying an organization's strengths may illuminate its weaknesses and the elements that must be reformed in order to achieve parity. Cameron \& Quinn contend that employees and leaders can participate in the OCAI simultaneously to diagnose the current culture and help highlight discrepancies between leadership and subordinates. Furthermore, employees and leaders can complete the OCAI to understand how each organizational member feels the culture should be in order to ensure success.

Engaging in the practice of producing current and preferred profiles can lead to deeper understanding of what the organization must do to actualize cultural reform. This can help identify a few key strategies to facilitate change, small key wins to be implemented immediately, managerial competencies needed to lead the change and manage the reformed culture, measures and metrics for accountability, and a communication strategy for the organization as a whole. It is important to note that changing culture is difficult and long-term. However, due process can facilitate meaningful change as evidenced by Cameron \& Quinn who emphasize that the key differences between successful and unsuccessful organizations are that unsuccessful ones will "launch right into a new change program without considering the need to develop a consensual view of the current culture, the need to reach consensus of what change means and doesn't mean, and the specific changes that will be started, stopped, and continued".

A separate tool, The Positive Organization Generator ${ }^{58}$ is meant to help create a positive culture by identifying positive practices that people "believe in and desire to implement within their own zone of control. This is accomplished by taking an assessment, creating a vision, reviewing the practices, selecting the practices that are liked, and then re-inventing them in order to complete an action plan. During the assessment process, leaders are encouraged to consider 
where the organization is and where it should go based on a list of positive and negative characteristics outlined in the tool including creative action, life balance, cohesive teamwork, and authentic relationships versus confusion, chaos, exclusion, and conflict. Once this is completed, a vision for the direction of the organization can be created using positive practices including creating a sense of purpose, nurturing authentic conversations, seeing possibility, embracing the common good, and trusting the emergent process. These positive practices should be reinvented to fit the needs of the organization in order to help realize the vision created in the previous step. Equipped with the tools to better understand the underlying issues and concerns with the current culture, organizations can begin to move towards creating a more welcoming and positive workplace. By using cultural audits, climate surveys, the OCAI, and the Positive Organization Generator, organizations can include employee ideas and observations in organizational reforms and attend to the areas needing to be addressed.

\section{Conclusion}

In order to promote the inclusion and success of women and URM in STEM, organizational structure, culture, and behavior must be analyzed for patterns that negatively affect and constrain marginalized groups. As outlined above, bias, gender heuristics, microaggressions, and many other tolerated (and sometimes subconscious) practices work together to enforce barriers for women and URM and contribute to their attrition from STEM fields. When considering how to implement change initiatives, it is important to remember that organizational transformation is a long-term commitment with many steps, each crucial and connected to the other and the success of the identified goal. Some organizations have found it helpful to celebrate small wins along the way--changes that are tangible and visible in an effort to maintain momentum and enthusiasm. Notwithstanding, it should be noted that the onus of any reform must not fall on underrepresented groups. Critical to the success of shifting the workplace paradigm are leaders, stakeholders, and those apart of the majority who commit to remaining dedicated and involved. As Johnson and $\mathrm{Smith}^{33}$ outline, in organizations where men are deliberately engaged in gender inclusion programs, $96 \%$ see progress compared to only $30 \%$ of organizations without male engagement. Of course, the same is true for leaders and managers; without top-down support, initiatives are unlikely to succeed.

Although this review has mainly focused on the disproportionately adverse effects of traditional workplace conservatism on women and URM, it is relevant to underscore that sexism and systems of oppression negatively impact all employees. Therefore, when implementing a diversity initiative, emphasizing its positive influences on the quality of the work environment for everyone may elicit more support especially since those in the majority may feel uncomfortable or resistant to change. Bond and Pyle ${ }^{35}$ encourage organizations to validate the feelings of loss and disruption that come from journeying into the unknown while highlighting the benefits of diversity in an inclusive effort to acknowledge every employee. Although implementing change is not an easy feat and the resources, time, commitment, and creativity required should not go unacknowledged, the benefits of creating a workplace that welcomes and 
supports diversity and inclusion are indispensable. To begin aiding the success and increasing the representation of women and minorities, organizations must be prepared to address structure, culture, and behavior to help foster a better and fairer future. 


\section{Resource List}

Allen-Ramdial, SA. A., Campbell, A. G. (2014) Reimagining the Pipeline: Advancing STEM Diversity, Persistence, and Success. BioScience 64(7), 612-618. DOI:10.1093/biosci/biu076

Beasley, M.A. Fischer, M.J. (2012). Why they Leave: The Impact of Stereotype Threat on the Attrition of Women and Minorities from Science, Math and Engineering Majors. Soc Psychol Educ (15), 427-448. DOI 10.1007/s11218-012-9185-3

Bilimoria, D., Buch, K.K. (2010) The Search is On: Engendering Faculty Diversity Through More Effective Search and Recruitment. Change: The Magazine of Higher Learning, 42(4), 2732. DOI: $10.1080 / 00091383.2010 .489022$

Bilimoria, D., Joy, S., Liang, X. (2008). Breaking Barriers and Creating Inclusiveness: Lessons of Organizational Transformation to Advance Women Faculty in Academic Science and Engineering. Human Resource Management, 47(3), 423-441. DOI: 10.1002/hrm.20225

Blake-Beard, S.; Bayne, M. L.; Crosby, F. J.; Muller, C. B. (2011). Matching by Race and Gender in Mentoring Relationships: Keeping our Eyes on the Prize. Journal of Social Issues, 67( 3), pp. 622-643.

Bond, M.A., Pyle, J.L. (1998). Diversity Dilemmas at Work. Journal of Management Inquiry, 7(3), 252-269.

Bosak, J., Kulich, C., Rudman, L., Kinahan, M. (2018). Be an advocate for others, unless you are a man: Backlash against gender-atypical male job candidates. Psychology of Men \& Masculinity, 19(1), 156-165. Doi: 10.1037/men0000085

Bowles, H. R., Thomason, B., Bear, J.B. (2017). Reconceptualizing What and How Women Negotiate for Career Advancement. Academy of Management Journal, 62(6) 1645-1671 DOI: $10.5465 / \mathrm{amj} .2017 .1497$

Cameron, K. S., Quinn, R. E. (2011). Diagnosing and Changing Organizational Culture: Based on the Competing Values Framework ( $3^{\text {rd }}$ edition). John Wiley \& Sons, Incorporated.

Cech, E. A. (2013). Ideological Wage Inequalities? The Technical/Social Dualism and the Gender Wage Gap in Engineering. Social Forces 91(4), 1147-1182. DOI:10.1093/sf/sot024

Chang, E. H., Milkman, K. L. (2020) Improving Decisions That Affect Gender Equality in the Workplace. Organizational Dynamic, 49(1). DOI: 10.1016/j.orgdyn.2019.03.002

Chapman, R. N. (2018). The Thrive Mosaic Developmental Framework: A Systems Activist Approach to Marginalized STEM Scholar Success. American Behavioral Scientist, 62(5), 600611. DOI: $10.1177 / 0002764218768859$ 
Coe, I. R., Wiley, R., Bekker, L. (2019). Organizational Best Practices Towards Gender Equality in Science and Medicine. Lancet, 393, 587-593.

Correll, S. J., Weisshaar, K.R., Wynn, A.T. (2020). Inside the Black Box of Organizational Life: The Gendered Language of Performance Assessment. American Sociological Review, 85(6) $1022-1050$

Dobbin, F., Kalev, A., Kelly, E. (2007). Diversity Management in Corporate America. Contexts, 6(4), 21-27.

Dobbin, F., Schrage, D., Kalev, A. (2014). Resisting the Iron Cage: The Effects of Bureaucratic Reforms to Promote Equity. SSRN DOE: 10.2139/ssrn.2513869

Dom, FRM., Ahmad, A. (2020). The Importance of Human Capital Management in Developing Quality Human Capital. International Journal of Business and Economy, 2(1), 42-46

Duch, J., Han, X., Zeng, T., Sales-Pardo, M., Radicchi, F., Otis, S., Woodruff, T.K., Amaral, L.A.N. (2012). The Possible Role of Resource Requirements and Academic Career-Choice Risk on Gender Differences in Publication Rate and Impact. PLOS ONE, 7(12)

Elvira, M., Town, R. (2001). The Effects of Race and Worker Productivity on Performance Evaluations. Industrial Relations, 40 (4), 571-590

Ensari, N. K., Miller, N. (2006). The Application of the Personalization Model in Diversity Management. Group Processes and Intergroup Relations, 9(4), 589-607. DOI: $10.1177 / 1368430206067679$

Estrada, M., Hernandez, P.R., Schultz, P.W. (2018). A Longitudinal Study of How Quality Mentorship and Research Experience Integrate Underrepresented Minorities into STEM Careers. CBE Life Sci Educ., Spring: 17(1): ar9 DOI:10.1187/cbe.17-04-0066

Fouad, N.A., Singh, R. (2011) Stemming the Tide: Why Women Leave Engineering. University of Wisconsin-Milwaukee

Frehill, L.M., Jeser-Cannavale, C., Malley, J.E. (2007). Measuring Outcomes: Intermediate Indicators of Institutional Transformation, Transforming Science and Engineering: Advancing Academic Women (Ann Arbor, MI: U. Michigan), pg. 298-323

Friedman, R. A., Craig, K.M. (2004). Predicting Joining and Participating in Minority Employee Network Groups. Industrial Relations, 43(4), 793-816

Funk, C.; Parker, K. (2018) Women and Men in STEM Often at Odds over Workplace Equity. Pew Research Center

Glass, J. L., Sassler, S., Levitte, Y., Michelmore, K.M. (2013). What's So Special about STEM? A Comparison of Women's Retention in STEM and Professional Occupations. Soc Forces. 2013 ; 92(2): 723-756. DOI:10.1093/sf/sot092. 
Gilbert, J. A., Ivancevich, J. M. (2000). Valuing Diversity: A Tale of Two Organizations. The Academy of Management Executive, 14(1), 93-105.

Green, T. K., Kalev, A. (2007). Discrimination-reducing Measures at the Relational Level. Hastings Law Journal, 59(6), 1435-1462.

Heilman, M.E. (2001). Description and Prescription: How Gender Stereotypes Prevent Women's Ascent Up the Organizational Ladder. Journal of Social Issues, 57(4), 657-674

Heilman, M.E., Wallen, A.S., Fuchs, D., Tamkins, M.M. (2004). Penalties for Success: Reactions to Women Who Succeed at Male Gender-Typed Tasks. Journal for Applied Psychology, 89(3), 416-427. DOI: 10.1037/0021-9010.89.3.416

Hill, C., Corbett, C., St. Rose, A. (2010). Why So Few? Women in Science, Technology, Engineering, and Mathematics. AAUW: Washington D.C.

Hofmann, Y. E., Strobel, M. (2020) Transparency Goes a Long Way: Information Transparency and its Effect on Job Satisfaction and Turnover Intentions of the Professoriate. Journal of Business Economics, 90, 713-732. DOI: 10.1007/s11573-020-00984-0

Holvino, E., Ferdman, B. M., Merrill-Sands, D. (2004). Creating and sustaining diversity and inclusion in organizations: Strategies and approaches. In M. S. Stockdale \& F. J. Crosby (Eds.), The psychology and management of workplace diversity (p. 245-276). Blackwell Publishing.

Huang, J., Gates, J.G., Sinatra, R., Barabasi, A-L. (2020). Historical Comparison of Gender Inequality in Scientific Careers Across Countries and Disciplines. PNAS, 117(9), 4609-4616

Hunt, J. (2016). Why Do Women Leave Science and Engineering? ILR Review, 69(1), 199226. DOI: $10.1177 / 0019793915594597$

Ibarra, H. (1995). Race, Opportunity, and Diversity of Social Circles in Managerial Networks. The Academy of Management Journal, 38(3), 673-703.

Johnson, W. B.; Smith, D. G. (2018). How men can become better allies to women. Harv. Bus. Rev. https://hbr.org/2018/10/how-men-can-become-better-allies-to-women

Kalev, A., Dobbin, F., Kelly, E. (2006). Best Practices or Best Guesses? Assessing the Efficacy of Corporate Affirmative Action and Diversity Policies. American Sociological Review, $71,589-617$

Kidder, D. L.; Lankau, M.; Chrobot-Mason, D.; Mollica, K.; Friedman, R. A (2004). Backlash Toward Diversity Initiatives: Examining the Impact of Diversity Program Justification, Personal and Group Outcomes. The International Journal of Conflict Management, 15(1). 77-102. 
Lichtenstein, G.; Chen, H.; Smith, K.; Maldonado, T.,. (2013). Retention and Persistence of Women and Minorities Along the Engineering Pathway in the United States. Cambridge Handbook of Engineering Education Research, Chapter 6.

Lyness, K.S., Judiesch, M.K. (1999). Are Women More Likely to Be Hired or Promoted into Management Positions? Journal of Vocational Behavior, 54, 158-173

Massachusetts Institute of Technology (1999). A Study on the Status of Women Faculty in Science at MIT.

National Science Foundation (January, 2020). The State of U.S. Science and Engineering. (NSB 2020-1)

Nielsen, M. W.; Alegria, S.; Borjeson, L.; Etzkowitz, H.; Falk-Krzesinski, H. J.; Joshi, A.; Leahey, E.; Smith-Doerr, L.; Woolley, A. W.; Schiebinger, L.,. (2017). Gender Diversity Leads to Better Science. PNAS, 114(8), 1740-1742. DOI: 10.1073/pnas.1700616114

Nishii, L. H. (2013). The Benefits of Climate for Inclusion for Gender-diverse Groups. Academy of Management Journal, 50(6), 1754-1774. DOI: 10.5465/amj.2009.0823

Picciano, M. Why you need to upgrade your accountability system MMI Inc. [Online]. https:/www.matrixmanagementinstitute.com/blog/why-you-need-upgrade-your-accountabilitysystem/ (accessed March 5, 2021).

Pickett, M. (2019). 'I Want What My Male Colleague Has, and That Will Cost a Few Million Dollars.' New York Times Magazine. https:/www.nytimes.com/2019/04/18/magazine/salkinstitute-discrimination-science.html

Quinn, R. E. (2015). The Positive Organization: Breaking Free from Conventional Cultures, Constraints, and Beliefs. Berrett-Koehler Publishers, Incorporated.

Rock, D., Grant, H., Grey, J. (2016). Diverse Teams Feel Less Comfortable — and That's Why They Perform Better. Harvard Business Review. https://hbr.org/2016/09/diverse-teams-feel-lesscomfortable-and-thats-why-they-perform-better

Schneider, A. K. (2017). Negotiating While Female. Marquette University Law School, 70 (3), 697-719.

Smith-Doerr, L.; Alegria, S.; Sacco, T., How Diversity Matters in the US Science and Engineering Workforce: A Critical Review Considering Integration in Teams, Fields, and Organizational Contexts. Engaging Science, Technology and Society 2017, 3, 139-153.

Stockard, J.; Green, J.; Lewis, P.; Richmond, G. L., (2008). Promoting Gender Equity in Academic Departments: A Study of Department Heads in Top-Ranked Chemistry Departments. Journal of Women and Minorities in Science and Engineering, 14, 1-27. 
Sturm, S., (2006). The Architecture of Inclusion: Advancing Workplace Equity in Higher Education. Harvard Journal of Law and Gender 2006, 29, 247-334.

Sturm, S. (2007). The Architecture of Inclusion: Interdisciplinary Insights on Pursuing Institutional Citizenship, 30 Harv. J.L. \& Gender 409-424. https://scholarship.law.columbia/edu/faculty_scholarship/1111

Thomas, R.; Cooper, M.; Konar, E.; Bohrer, A.; Mohsenin, A.; Yee, L.; Krivkovich, A.; Starkova, R.; Huang, J.; Zanoschi, D. (2019). Women in the Workplace. ${ }^{17}$ McKinsey \& Company. https://wiw-report.s3.amazonaws.com/Women_in_the_Workplace_2019.pdf

Turban, S., Freeman, L., Waber, B. (2017, October 26). A Study Used Sensors to Show That Men and Women Are Treated Differently at Work. Harvard Business Review. https://hbr.org/2017/10/a-study-used-sensors-to-show-that-men-and-women-are-treateddifferently-at-work

Wanguri, D. M. (1996). Diversity, Perceptions of Equity, and Communicative Openness in the Workplace. The Journal of Business Communication, 33(4), 443-457

Watson, C. (2020, May 12). Empathy and Grit-Not Just Publication Records-Should be Considered in Researcher Assessment. Nature Index. https://www.natureindex.com/newsblog/empathy-resilience-should-be-considered-researcher-scientist-fairer-assessment-metrics

Whittington, K. B., Smith-Doerr, L. (2008). Women Inventors in Context: Disparities in Patenting across Academia and Industry. Gender and Society 22(2). 194-218. DOI: $10.1177 / 0891243207313928$ 


\section{Appendix A: Annotated Bibliography}

1. Allen-Ramdial, S. A.; Campbell, A. G., Reimagining the Pipeline: Advancing STEM Diversity, Persistence, and Success. BioScience 2014, 64 (7), 612-618.

This article focuses on detailing strategies aimed at increasing diversity within the scientific community by highlighting four different action areas: aligning institutional culture and climate, building interinstitutional partnerships, building and sustaining critical mass, and ensuring, rewarding and maximizing faculty involvement. The authors define institutional culture as "the collection of shared values and beliefs that is the blueprint that guides actions," and climate as "the practices and behaviors that determine the prevailing attitudes in the environment." Climate is directly related to someone's sense of belonging and these two concepts, culture and climate, must be aligned in order to improve outcomes for URM in STEM fields. In order to achieve this, the authors suggest annual climate assessments surveys administered by a third party, which would hopefully maximize anonymity and response rates, and minimize unintentional data interpretation biases. The second focus area, building interinstitutional partnerships, emphasizes breaking down traditional training silos and addressing cultural differences that exist as barriers to URM students by fostering relationships across institutions. Attaining and sustaining critical mass ensures that URM students and faculty are not isolated, which is paramount to the success of traditionally marginalized groups. Lastly, increasing faculty involvement in diversity related activities allows diversity to be mainstreamed. The authors posit that by adopting these practices, diversity can begin to be institutionalized and a strong and diverse scientific workforce can flourish.

2. Beasley, M. A.; Fischer, M. J., Why they Leave: The Impact of Stereotype Threat on the Attrition of Women and Minorities from Science, Math and Engineering Majors. Soc. Psychol. Educ. 2012, 15, 427-448.

This study examines the attrition of women and minorities in STEM majors by focusing on the impact of stereotype threat, which is the "anxiety caused by the expectation of being judged based on a negative group stereotype." The researchers note that the lack of women and URM representation in the STEM workforce is in part, a consequence of low retention rates of women and URM students in STEM fields. The effect of stereotype threat can negatively impact a student causing them to withdraw from certain majors adding to the "leak" in the pipeline. The researchers find that "the experiences of stereotype threat among Black men and women, as well as White and Hispanic women have a significant influence on STEM attrition."

3. Bilimoria, D.; Buch, K. K., The Search is On: Engendering Faculty Diversity Through More Effective Search and Recruitment. Change: The Magazine of Higher Learning 2010, 42 (4), 27-32.

This article focuses on how traditional university faculty hiring and recruitment strategies ultimately fail to bring in diversity for a variety of reasons. The traditional model includes 
placing a job advertisement, accepting applications, receiving nominations from colleagues at other universities, reviewing and ranking candidates, developing a short list, interviewing, and finally, making an offer. However, the researchers claim that this approach is passive and it is "assumed that appropriate applicants will apply for an advertised position." Additionally, the faculty search committees are usually not diverse, lack expertise in hiring and recruiting strategies, and are bias prone, which affects the applications reviewed and ultimately, those who are shortlisted. To mitigate these harmful effects, the report suggests several revisions to traditional hiring and recruiting strategies. First, search committees must be aggressively seeking talented and diverse candidates. This can be achieved by sending representatives to conferences or networks with large numbers of URM scholars or doctoral candidates and building relationships. After attending such events, a staff member of the diversity office must serve as a liaison between candidates and hiring departments. Second, the search committee and hiring committee must be as diverse as possible. Training must be provided in order to build awareness around internal biases and fair hiring practices. Lastly, the university administration must hold all participants in the search process accountable for its outcomes. This can be done by gathering data and having on going assessments of the faculty search process and its results. Some key findings from this study include: "a statistically significant linear relationship between the percent of female and URM applicants in the candidate pool and their degree of inclusion on the short list," "the level of representation of female and URM applicants on the short list is associated with the likelihood of hiring a female or URM candidate," "increasing gender diversity in candidate pools can have broad ranging, beneficial effects on the hiring of other URM faculty groups at the university," and "job offer rejections may occur for many reasons including a lack of diversity at the department or school level, perception of campus climate, a lack of childcare, or duale career issues pertaining to a trailing partner or spouse." These findings imply that increasing diversity must happen early on in the process. In order to have ongoing accountability, the report also suggests developing a policy group that focuses on "examining recruitment policies and practices and recommending changes necessary to support our gender diversity goals."

4. Bilimoria, D.; Joy, S.; Liang, X., Breaking Barriers and Creating Inclusiveness: Lessons of Organizational Transformation to Advance Women Faculty in Academic Science and Engineering. Human Resourse Management 2008, 47 (3), 423-441.

This chapter reviews the institutionalization of change and the outcomes of program initiatives for 19 universities that participated in the National Science Foundation's ADVANCE initiative. After providing an overview of the "leaky pipeline" phenomenon in academia, the authors begin to dissect the different facets of institutional transformation that the highlighted universities took to increase women's representation and inclusion in science and engineering. It is relevant to note that ADVANCE Institutional Transformation awards are intended to fund programs that culminate in the "full participation of women in all levels of faculty and academic administration, particularly at the senior academic ranks, through the transformation of institutional practices, policies, climate, and culture." The various transformational initiatives that the authors describe include pipeline and climate initiatives. Pipeline initiatives refer to 
"increasing the inflow of women into the pipeline, improving the institutional structures and processes related to academic career transition points (recruitment, promotion, and tenure), and better equipping women to successfully progress in the pipeline." Developing mentoring, coaching, and networking programs are some of the suggested ways to mend the issues with the pipeline. Climate initiatives focus on "improving the awareness and practices of male colleagues through education, training, and development; engaging in efforts to make departments (microclimates) more collegial, egalitarian, equitable, and transparent; and increasing organizational aware- ness of diversity and inclusion issues." The authors include a helpful model on page 427 of the various facets of each initiative. The outcomes of institutional transformation are detailed next and these include new structures, positions, and groups, new and modified policies, accepting change as a part of everyday routine, and recording best practices. The authors took care to explain the internal and external factors that helped facilitate transformational change. It is noted that "senior administrative support, collaborative leadership, flexible vision, and visible action" are key internal components, as well as change agents spread across the ranks of the organization, a message reiterated in Creating and Sustaining Diversity Initiatives. External factors include, in this case, support from NSF and peer institutions that are simultaneously implementing changes. Lastly, methods of measuring and tracking change are detailed and it is stated that the ADVANCE institutions implemented "three types of research activities: tracking key indicators of inclusion, evaluating effectiveness of specific change initiatives, and improving data collection and analysis systems." While some of these tracking methods rely on quantitative data, the authors also mention qualitative methods including interview, focus groups, resource equity studies, and climate surveys. The chapter concludes with recommendations for increasing and retaining diversity. For example, the development and inclusion of a team of senior faculty leaders and administrators focusing in issues relating to women's representation, increasing the number of organizational change agents focusing on similar issues while helping to create resolutions, engaging male members at all levels, fostering senior level support, and tracking data, are mentioned.

5. Blake-Beard, S.; Bayne, M. L.; Crosby, F. J.; Muller, C. B., Matching by Race and Gender in Mentoring Relationships: Keeping our Eyes on the Prize. Journal of Social Issues 2011, 67 (3), 622-643.

This study analyzes the mentor-mentee relationship and the effects of gender and race matching on student experience and academic outcomes. The researchers distinguish three different facets of a mentor relationship that contribute to the development and success of the protégé: career functions, psychosocial functions, and role modeling functions. To the extent that race and gender influence the understanding and shared experiences of the mentor and protégé, it is important to observe how similarities may affect outcomes. The researchers note that there is conflicting evidence as to whether or not matching plays a huge role in this relationship. Their results show that while students who had mentors of a similar race and/or gender recorded having received more help, ultimately, it appears that a match between what the protégé needs and what the mentor can provide is more salient. They take care to emphasize that if demographic characteristics enable a more candid and open relationship, then it may be 
important to take race/gender into consideration but overall, matching made no difference on academic outcomes.

6. Bond, M. A.; Pyle, J. L., Diversity Dilemmas at Work. Journal of Management Inquiry 1998, 7 (3), 252-269.

This piece discusses the efforts taken to promote diversity in the workplace focusing specifically on equal employment opportunity (EEO), affirmative action (AA), and diversity management. The milieu of this article rests in the lack of progress made, even in the face of current strategies, in truly diversifying workforces and attempts to explain what actions must be taken in order for organizations to truly evolve. The authors begin by exploring diversity policy trends and explaining the difference between EEO and AA policies and diversity management strategies. EEO policies are more passive in nature while AA policies are more active and therefore less understood; many mistakenly believe that AA policies require quotas or the hiring or unqualified, confirming what the authors of The Backlash Towards Diversity Initiatives, describe. Diversity management, on the other hand, digresses from promoting equity and fairness and focuses more on "improving corporate efficiency and profitability." While there seems to be legal mandates forcing organizations to diversify and an internal understanding that diversity equates to being more competitive, the enduring homogeneity of the workforce can be attributed to three dilemmas. The first is the concept of false dualisms or "assumptions about sameness, difference, and equality." The authors explain that the "sameness paradigm emphasizes that all people should be treated the same and that inequity results when groups are treated differently" whereas the difference paradigm "emphasizes the existence of diversity among people and the need to design strategies for equity that attend to those differences." The problem here rests with organizations believing that these two concepts are dichotomous and mutually exclusive. The authors stress that 'equality is not the elimination of difference, and difference does not preclude equality' and urge managers and supervisors to see differences in the context of similarities and vice versa.

The second dilemma, unanticipated fallout: diversity policies and programs that elicit reactions impeding progress, focuses on the reactions of employees to different diversity initiatives. Ranging in employees feeling that initiatives fall short and are superficial to backlash by mostly White men, the authors highlight how often diversity programs are unpopular because of their structure and lack of real commitment to changing organizational culture. These initiatives are essentially asking workers to become more sensitive and understanding of differences while finding common ground however, "when in house diversity programs are well integrated into other organizational development efforts and have top-level support, people are challenged to change deeply set patterns," which can be very uncomfortable. Lastly, the third dilemma, cultural change: organizational values hampering workforce diversity efforts, continues the conversation by focusing on why EEO, AA and diversity management programs have not been effective. Here, it is argued that "underlying community and organizational attitudes and values have not changed significantly," therefore a gap often emerges between "formally stated goals of diversity initiatives and the values actually adopted during day-to-day 
organizational life." In order to counter this, efforts must cut across all organizational levels and communal attitudes and the notion of interdependence must be fostered.

The authors conclude by acknowledging that organizations must find ways to harness the benefits of diversity while validating "the loss of comfort and sense of disruption that come from dealing with the unfamiliar." Additionally, three ways in which organizational processes must shift in order to truly support diversity are identified. These include creating management practices and organizational models that appreciate the context in which people exist and live, developing an understanding that diversity signals a shift in power, and institutionalizing the need for a diverse workforce in organizational practices.

7. Bosak, J.; Kulich, C.; Rudman, L.; Kinahan, M., Be an Advocate For Others, Unless You Are a Man: Backlash Against Gender-atypical Male Job Candidates. Psychology of Men \& Masculinity 2018, 19 (1), 156-165.

This report discusses how gender biases affect everyone, including men, and argues that it is in everyone's best interest to address gender biases and work to eliminate them. The researchers found that women that are self-advocating and possess "male tendencies" are less liked than the other-advocating women who are seen as more docile. The research reiterates what Schneider writes in "Negotiating while female," that women face an impossible situation of needing to act agentic in order to be taken seriously but then face repercussions for being too "masculine." The research also finds that men who act in "a-typical" ways, for example advocating for others instead of just focusing on themselves, report backlash, as well, supporting the social norms and preventing more gender diversity. They find that "when men embody desired leadership behaviors by advocating for others, they risk recommendations for dismissal as a result of reduced agency and competence." This is important seeing as men still occupy more leadership roles than women. Changing the paradigm to promote equality and equity will include addressing how biases influence the expectations of both genders.

8. Bowles, H. R., Thomason, B., Bear, J.B. (2017). Reconceptualizing What and How Women Negotiate for Career Advancement. Academy of Management Journal, 62(6) DOI: $10.5465 / \mathrm{amj} .2017 .1497$

This research focuses on gender differences in negotiation, similar to "Negotiating While Female," by Andrea Schneider. Through 6 different studies, the researchers analyze the differences between what men and women will try and negotiate for, and what methods they will employ. For instance, the researchers introduce three different types of behavior-asking, bending, and shaping - that relate to how the negotiator "conforms to, deviates from, or attempts to redefine organizational norms." Asking refers to items that are related to standard requests, bending items to make exceptional personal requests, and shaping items to make strategic proposals for a new leadership role. The researchers observe that gender does in fact affect negotiation outcomes and that "gender differences in the trajectories of men's and women's labor participation are the leading factors in explaining the contemporary gender pay gap." For 
women, the ambiguity about negotiating norms inhibits women from participating in negotiations, which adds to the gender wage gap. Men, on the other hand, are often deterred from negotiating for more job flexibility because of the social backlash they receive. Overall, negotiations over role responsibilities and requirements are overwhelmingly behind why men and women negotiate. Workload is a close second for women, particularly around family obligations. Women more often relied on "bending" to overcome at least two barriers to women's career advancement, which include "work-family conflicts and lack of traditional professional qualifications for counter-stereotypical roles." The researchers hypothesize that "in organizational contexts in which advancement processes are implicitly structured on a masculine-stereotypical model, women more often than men may need to employ their negotiating competences to break new paths." However, they also hypothesize that if women employed more "shaping," they may face less resistance to leadership claims because this employs a strategy that suggests how they advancement will be mutually beneficial rather than competitive. The researchers conclude that the current trainings that focus on how to teach women how to negotiate imply that there is something wrong with women instead of looking at the whole system. They suggest working with leaders to "implement public and organizational policies that open doors for women and men to negotiate mutually beneficial work arrangements with their organizations that help them grow and contribute professionally as whole people."

\section{Cameron, K. S.; Quinn, R. E., Diagnosing and Changing Organizational Culture: Based on the Competing Values Framework. Jossey-Bass: San Francisco, CA, 2011.}

In their book, Cameron and Quinn explore how to change organizational culture in an effort to support the effectiveness and success of each organization. The authors utilize the Competing Values Framework and rely heavily on the Organizational Culture Assessment Instrument, which produces an overall organizational cultural profile. The authors provide step by step approaches for diagnosing organizational culture and how to manage reform in order help realize the desired identified changes. This technique builds responsibility and accountability both on the organization as a whole, as well as the managers who must develop skills to create a welcoming environment for all. The authors suggest including employees in the reform efforts and having employees participate in the exercises provided. This easy to read resource is incredibly helpful when considering how to understand an organization's culture and what steps are needed to move the culture in the desired direction.

10. Cech, E. A., Ideological Wage Inequalities? The Technical/Social Dualism and the Gender Wage Gap In Engeering. Social Forces 2013, 91 (4), 1147-1182.

In this study, Cech analyzes how cultural ideologies in engineering may contribute to wage inequalities within the field. Cech shows how patterns of sex segregation and gendered wage allocation in engineering fall along an ideological distinction between technical and social engineering subfields and work activities. The research also shows that women more likely to be in the social areas but it is within the technical areas that women are paid less. This leads Cech to posit that the culture within engineering assumes women can do the social but not the technical aspects of the field. In comparing this finding in engineering to other scientific fields such as 
biology and the physical sciences, Cech finds that this disciplinary culture does not exist and there is no relationship between gender inequality and the technical/social dualism bolstering Cech's argument.

11. Chang, E. H.; Milkman, K. L., Improving Decisions that Affect Gender Equality in the Workplace. Organizational Dynamic 2020, 49 (1).

This article discusses how gender bias impacts women in the workplace and provides strategies for mitigating the ensuing deleterious effects. The authors explain that stereotyping can lead to men being favored over women in the workplace, which has long-term consequences for the advancement of women's careers. The researchers outline four main effects of gender bias. The first is redefining merit where managers or hiring personnel redefine what qualifications are necessary to succeed based on the gender of the applicant. The second, differential credit allocation, suggests that "when there is ambiguity about which members of a group contributed what components to the group's success, women are rated as being less competent, less influential, and less likely to have played a leadership role on the task than men in the same group." This supports other research that was also argued that ambiguity promotes disparate outcomes. The third effect of bias is punishing women for violating stereotypes, which can hurt their chances for promotion. Within this category, Chang and Milkman write that women face pressure to spend more time than men helping others and working on tasks that will not have high returns for their careers. Furthermore, they face backlash if they fail to help. The last discussed effect is treating diversity as a box to check, which can lead to tokenism and to women being judged more negatively than in gender-balanced groups.

In order to prevent gender disparities from continuing or existing in the first place, the authors include six suggestions for organizations to execute. The first, blind decision making, can help avoid relying on gender stereotypes by not considering an applicant's gender when reviewing their CV. The authors offer a word of caution by noting that "this strategy may not help when institutionalized differences might lead women to have systematically worse qualifications than men," in which case gender may be important to consider. The second suggestion is substituting or going through the exercise of asking yourself if you would make the same decision if the applicant were of the opposite gender. The third encourages leadership to articulate new social norms where "work- related behaviors are equally appropriate whether engaged in by men or by women," so that women do not receive backlash for violating gendered behavior norms. The fourth suggestion relates to evaluating candidates jointly. The researchers highlight how participants in one study, when presented with both a male and a female applicant, gender bias was erased whereas when presented individually, stereotypes affected decision making. The fifth suggestion is for organizations to individualize information; "when we have access to specific information about a person, we are less likely to rely on stereotypes to fill in our knowledge gaps." Lastly, the authors encourage organizations to educate themselves and their employees about the ways in which gender bias affects the success of men and women in the workplace. 
12. Chapman, R. N., The Thrive Mosaic Develomental Framework: A Systems Activist Approach to Marginalized STEM Scholar Success. American Behavioral Scientist 2018, $62(5), 600-611$.

The Thrive Mosaic is a developmental framework for STEM scholars that works towards equitable development, access, and opportunity. The framework takes a systems theory approach and seeks to bring together a scholar's network in an effort to support their development, advocacy, and self-care to preempt marginalization and obstructionist practices. Chapman stresses that marginalized scholars often do not fit institutional norms and expectations, which poses a challenge when trying to recruit White faculty to serve as mentors. However, positive social exchange is an important tenet of socialization and advancement within academia. Because of this, the Thrive Mosaic model strives to deconstruct the traditional mentorship relationship by creating 6 unique roles that different partners can adopt: associate, advocate, connector, mentor, coach, and targeted training. By expanding marginalized scholars' networks and increasing the number of ally's, hopefully the barriers to scholar success will dissipate and academia can become more diverse.

13. Coe, I. R.; Wiley, R.; Bekker, L., Organizational Best Practices Towards Gender Equality in Science And Medicine. Lancet 2019, 393, 587-593.

This short review focuses on "effective strategies to shift organizational culture and climate towards gender equality using approaches that include legislation, allyship, leadership by scientific societies, professional development of core competencies in equity principles, and inclusive leadership," specifically in medical and scientific fields. The authors begin by noting that implementing meaningful change in these fields can pose a particular challenge because there is a sense of equitable meritocracy in science, which often proves more mythical than factual. While seemingly innocuous, this fallacious belief creates an obstacle for those advocating for change, especially from members of the scientific and medical communities who are committed to remaining ignorant. The authors describe this conflict by noting that "the myth of meritocracy is as entrenched in academic science and medicine as it is in Silicon Valley and Wall Street. Those who continue to believe the combined myths of meritocracy and equity in science and medicine thus feel oppressed by initiatives aimed at achieving equality, resulting in pushback that can be retaliatory and hostile." Due to this, leaders, especially those who are male, with power, privilege, and social capital, that advocate on behalf of women, are critical to changing the culture of an organization. Furthermore, the idea of inclusive leadership is posited as being critical for effectuating change. Leaders who are inclusive may initiative programs and policies such as "intentional team building towards a shared understanding of EDI principles and actions, the redaction of features that identify gender or ethnicity based on resumes, and adopting of new policies around work." Allies are also highlighted as being an important component of organizational change. The authors propose allyship training that is framed as part of an organizational change and "recognizes who has and who abuses power and privilege (to unfairly advantage themselves and people from the same group) in the workplace. Moreover, we propose that allyship training should highlight the role and responsibilities of all members of the 
community, regardless of gender, ethnic origin, sexual orientation, ability, or age, in supporting and advocating for other members of the community."

14. Correll, S. J.; Weisshaar, K. R.; Wynn, A. T., Inside The Black Box Of Organizational Life: The Gendered Language of Performance Assessment. American Sociological Review 2020, 85 (6), 1022-1050.

In this study, researchers are interested in factors leading to bias in employee performance evaluations. The researchers contend that managers often have influence over the evaluation process; and, in absence of a formalized, well-defined and easy to use platform, negative biases can affect women and people of color at higher rates, leading to worse professional outcomes. They argue that if an evaluation process is ambiguous, managers will not only rely on "widely shared gender beliefs" which may "subtly frame their observations, interpretations, and valuations of employee behavior," but a manager's implicit bias may lead them to value certain behaviors differently for men and women resulting in disparate ratings based on gender. To depict this point, the researchers create a model called the Viewing and Valuing Social Cognitive Processing Model. Here, managers can evaluate if they view gender differences or not, and/or value traits differently by gender or not, to understand the ramifications of their behaviors on their evaluations for the different sexes.

After coding managers' written performance reviews at one Fortune 500 company, the researchers find that there were no gender differences in viewing or valuing when managers make broad general performance evaluations or when evaluations were made about core features of technical work. However, they did find three types of evaluations that were not gender neutral. These include evaluations about personality and communication style, future-oriented evaluations, and evaluations about who is truly exceptional rather than merely competent. Not only does this show bias in the process, but the researchers conclude that "managers appear to (1) expect men and women to enact their jobs as gendered people, and (2) police behaviors that fall outside of those expectations by calling out gender atypical behavior (aggressiveness for women, softness for men) and penalizing women's ratings for highly agentic behavior, such as taking charge." Additionally, the researchers found that "sponsorship had the largest positive effect on ratings for women out of all the codes we studied, including increasing the odds of women receiving the highest rating most strongly associated with promotion." They conclude that in order to reduce bias, organizations should reduce the ambiguity and uncertainty surrounding the process and increase transparency and accountability.

15. Dobbin, F.; Kalev, A.; Kelly, E., Diversity Management in Corporate America. Contexts 2007, 6 (4), 21-27.

This article is a summary of the researchers work which shows how some types of diversity programs are more effective than others. For example, the researchers discuss how assigning responsibility for diversity to specific councils or managers, or instituting formal mentoring programs are much more effective than diversity training session, diversity 
performance evaluations for managers, and network groups. The researchers note that companies that establish taskforces typically see small decreases in the number of white men in management, and large increases for every other group. It is important to note that white men dominate management at the outset so a small percentage decrease for white men can make space for big percentage gains for other groups. Furthermore, the researchers discuss how firms that put in diversity managers see increases for all groups of women, as well as black men.

16. Dobbin, F.; Schrage, D.; Kalev, A., Resisting The Iron Cage: The Effects of Bureaucratic Reforms to Promote Equity. SSRN 2014.

Drawing on sociological and psychological concepts, Dobbin et. al. find that initiatives focusing on special recruitment and training programs increase diversity while programs that limit managerial discretion in hiring and promotion such as job testing, performance evaluation, or grievance procedures will have negative effects. Increasing transparency without restricting managerial discretion in the form of job posting systems, which have been shown to make "minority and female employees aware of promotion opportunities" (9) don't reduce management diversity. They also find that monitoring by diversity managers or federal regulators improves bureaucratic reforms.

17. Dom, F.; Ahmad, A., The Importance of Human Capital Managment in Developing Quality Human Capital. International Journal of Business and Economy 2020, 2 (1), 4246.

This article explains the concept of human capital management and its importance for organizations' human resources department. The authors explain that human capital is "knowledge capital [which is compromised] of the intangible abilities and skills of the workers." Introduced by Theodore Schultz in 1961, the Human Capital Theory posits that trainings provided by employers will help drive the unique ideas and skills that workers bring to their organizations. Additionally, this theory emphasizes employee development, as well as the development of good relationships among workers, as a means to enhancing an organization's growth and competitiveness. The authors argue that human resources play a major role in developing human capital through leadership practices, employee engagement, knowledge accessibility, workforce optimization and organizational learning capacity. They write that managers should focus on talent management through recruiting, incentivizing and engaging employees. This will help with an organization's stability and subsequent growth. Therefore, it becomes imperative that human resources invest in their employees' and help foster positive relationships among them.

18. Duch, J. et. al. (2012)._The Possible Role of Resource Requirements and Academic Career-Choice Risk on Gender Differences in Publication Rate and Impact. PLOS ONE, $7(12)$

This study explores gender bias in STEM by investigating "field-dependent, genderspecific effects of the pressures individuals experience as they pursue a career in academia 
within seven STEM disciplines." The researchers find that gender differences in publication rate and impact are discipline specific. Additionally, the data shows that these lower publication rates of female faculty can be connected with the amount of research resources needed pointing to a lack of support by the institution. The authors conclude by suggesting that policies working to provide better opportunities for all ought to be created in order to retain women and foster a diverse workforce.

19. Elvira, M.; Town, R., The Effects of Race and Worker Productivity on Performance Evaluations. Industrial Relations 2001, 40 (4), 571-590.

Like the study "Bringing Managers Back In," the researchers in this study examine the effects of employee and supervisor race, and worker productivity, on performance ratings. Based on their statistical analyses, the researchers find that "interpretations of performance depend on the races of supervisor and subordinate." The results indicate that white supervisors tend to rate White employees higher than Black employees, and that Black supervisors rate Black employees higher than White employees. This confirms other literature that finds that "raters evaluate job performance of blacks less favorably than that of whites and that both black and white supervisors rate more favorably subordinates of their own race." The researchers note that this effect may arise from reliance on stereotypes. The importance of these findings highlight the cycle of inequality where "if differential ratings lead to lower promotions for black employees, blacks will be less likely to rise into managerial positions," and White employees will continue to be disproportionately represented in leadership positions.

20. Ensari, N. K.; Miller, N., The Application of the Personalization Model in Diversity Management. Group Processes and Intergroup Relations 2006, 9 (4), 589-607.

This report discusses the personalization model, which provides a framework for reducing prejudice and increasing interaction between "in-group" members and "out-group" members. This model is important to consider as research shows that "positive and cooperative contact between members of previously hostile groups reduces prejudice" and intergroup contact can prove especially helpful in reducing the "stress and performance pressures that typically are experienced more keenly by minority employees." The authors distinguish three different elements of personalization including self-other comparison, self-disclosure, and empathy and perspective taking. Self-other comparison allows members to compare and contrast similarities and differences in an effort to expand perspectives and identify commonalities. Self-disclosure hinges on building trust by sharing personal and intimate information. Trust is crucial for intergroup relationships seeing as fostering relationships with those who are seen as different can be uncomfortable and difficult and building trust "reduces anxiety and discomfort." To confirm this theory, the authors take care to reference research that shows that students who had more out-group friends during college, implying a relationship that includes trust, exhibit less outgroup bias and intergroup anxiety. The last element, empathy and perspective taking, relies fostering sympathetic and empathetic reactions to members in different groups through personalized contact. The authors stress that personalized contact can enhance employee effectiveness and interpersonal communication, as well as improve the working climate by 
providing channels for conflict resolution. In order to integrate the personalization model into organizational culture and structure, the authors suggest designing seminars, workshops and lectures educating employees about prejudice. In addition, providing employees opportunities to forge relationships by working on tasks together, or arranging meetings that are attended by various working groups can help foster cross group friendships and relationships. As with other articles that have studied organizational theory and equity, it is important to remember that analyzing dynamics and relationships at the organizational level is crucial if the true benefits of intergroup relationships and acceptance can be realized.

21. Estrada, M.; Hernandez, P. R.; Schultz, P. W., A Longitudinal Study of How Quality Mentorship and Resarch Experience Integrate Underrepresented Minorities Into Stem Careers. CBE Life Sci Educ. 2017, Spring 17 (1), ar9.

This study focuses on the disparity between URM students and non-URM students in STEM related fields. Using a tripartite integration model of social influence (TIMSI), the researchers measured the development of TIMSI key variables (science efficacy, identity, and values) and found that students who experience quality mentorship and engage in two semesters of research experiences are more likely to continue in STEM fields. The researchers explain how mentorship provides instrumental (resources, coaching, etc.) and psychosocial support that are important in developing a student's identity as a scientist, which can positively affect retention rates of URM students in STEM. The study ends by suggesting that more research and mentorship opportunities become available to URM students to increase retention in the field.

\section{Fouad, N. A.; Singh, R. Stemming the tide: Why Women Leave Engineering; University} of Wisconsin: 2011.

This report focuses on understanding why women leave engineering by comparing women who obtained a degree but never pursued engineering, women who left the field 5 years prior, and women currently working as engineers. For those who never entered the field, women in this study felt that the organizational climate of different engineering workplaces wasn't welcoming or diverse, and the lack of flexibility wasn't appealing. Similarly, many women who left the field left because they wanted to start a family and there weren't policies in place to make work-life balance more achievable. Work conditions such as too much travel, lack of advancement, and low salaries were some of the reasons women cited as factoring in to their decisions to leave. Still, even women who stayed in the field continue to express feelings of dissatisfaction over job flexibility, lack of gender diversity, workplace discrimination, and worklife balance. The report found that women occupied the least amount of executive positions and about half weren't in supervisory roles. It also found that workplace satisfaction is a key component of overall work environment and that workplace support in the form of relationships, training and advancement opportunities, and recognition of contributions were all highly important in fostering a sustainable work environment. Similar to what was discussed in the report Women in Sciences, the barriers women face often involve work family conflict and excessive work expectations without the necessary resources. Interestingly, this report found that 
"what women engineers experience on a daily basis at work, profoundly alters their feelings to the engineering profession as a whole. These feelings are not contained to the workplace and instead spillover to weaken their commitment to the profession." Apart from the unbalanced work-life expectations, women noted feeling that a lack of clarity around role objectives, responsibilities, and goals contributed to feeling detached and dissatisfied with their work experiences. This report ends with several recommendations which emphasize clarity, building supportive networks, revamping organizational culture, transparency, and increasing professional development opportunities.

\section{Frehill, L. M.; Jeser-Cannavale, C.; Malley, J. E., Measureing Outcomes: Intermediate Indicators of Institutional Transformation, . University of Michigan Press: 2007.}

This chapter focuses on ways administrators can measure change within their institutions using data from nine universities that were funded by NSF's ADVANCE program. The authors address how to track to the extent to which women are in positions similar to those of men and how equitable the institutional processes of advancement are for men and women. By comparing data from national averages as well as numbers from peer organizations, an organization can begin to analyze its own trends as they relate to external ones. However, it is also important for organizations to do internal assessments and track changes within the institution. In order to fully analyze these trends, the authors suggest comparing statistics to peer institutions and national averages as well as within the organization itself. Ways to do this include sex ratios, cohort analyses, or flow charts. These analyses can be done at the university, college, or department level and "may be helpful for identifying specific areas where interventions may have been successful as well as areas where further efforts may be needed."

\section{Friedman, R. A.; Craig, K. M., Predicting Joining and Participating in Minority Employee Network Groups. Industrial Relations 2004, 43 (4), 793-816.}

This study focuses on network groups and their effect on retaining and supporting URM. Network groups, as the authors describe them, are "established groups of employees that get together for various activities" and serve to "enhance the careers of members by providing social support, information, and leadership opportunities to members." The information sharing that occurs in these network groups is particularly important because as the authors note, it can be challenging for White workers, who make up the majority of the workforce, and URM employees to form close ties; this may lead to members of underrepresented groups having limited access to information. In addition, the social support and mentoring network groups offer leads to career development and community building among URM employees. While some may fear that this will lead to segregated, disgruntled pockets of workers, the results of the study indicate that URM employees do not join network groups out of frustration but rather out of a perceived group identity that may in fact make URM employees feel more comfortable with their work environment. The researchers posit that if this is the case, if network groups serve to build community and foster mentoring relationships, minority turnover should be reduced, and social embeddedness more deeply felt. It is important to note that despite the benefits of network groups, namely career development and community building, URM employees "are less likely to 
join if they feel that there may be some retribution for joining, and they are more likely to join if they feel support from peers and supervisors." Therefore, it is imperative that organizations work to make URM employees feel supported. The authors suggest that network group leaders share information and conduct outreach about the purpose and importance of the groups. The potential benefits of these communities cannot go unheeded for if minorities with a stronger sense of place and confidence can advance the furthest, the issues minorities face can be brought to the organizational leaders and "enhance the ties between top management and minority employees."

25. National Science Foundation. The State of U.S. Science and Engineering; 2020.

This report conducted by the National Science Foundation provides quantitative information on the state of the U.S. science and engineering fields over time. The report is organized into six sections beginning with education, which has information on the performance of students K-12 and science and engineering degrees awarded in the US. The report provides information on the important role community colleges play in many science and engineering degree-holders' academic histories. The second section focuses on the demographics of the science and engineering workforce and employment trends. The report finds that both the workforce and the number of women and unrepresented minorities has grown simultaneously. However, women and URM still remain underrepresented in the workforce compared to their overall presence in the workforce and the population. The next two sections focus on research and development, specifically the US position in a global context and the structure of performance and funding. The fifth section analyzes trends in global science and technology capabilities along with science and engineering research publications. Lastly, the sixth section focuses on innovated related indicators and US public attitudes in relation to science and technology.

\section{Funk, C.; Parker, K. Women and Men in STEM Often at Odds over Workplace Equity;} 2018. Pew

This report uses data on URM STEM employees to discusses prevailing attitudes towards the lack of diversity in STEM fields and compares the perspectives of different racial groups in response to factors affecting diversity in the workplace. The article notes that "most blacks in STEM positions consider major underlying reasons for the underrepresentation of blacks and Hispanics in science, technology, engineering and math occupations to be limited access to quality education, discrimination in recruitment and promotions and a lack of encouragement to pursue these jobs from an early age." In addition, the article states that "Blacks and Asians in STEM jobs, followed by Hispanics, are more likely than white STEM workers to say that their race or ethnicity has made it harder to find success in their job." Hiring and promotional practices are also discussed and the authors write that "among STEM workers, more say that whites are usually treated fairly in both the hiring and promotion processes in their own workplace than say the same for Asian Americans, Hispanics and blacks in each of these 
situations." The article ends with quotes from URM in the field that highlight suggestions for increasing diversity.

27. Glass, J. L., et. al. (2013). What's So Special about STEM? A Comparison of Women's Retention in STEM and Professional Occupations. Soc Forces. 2013 ; 92(2): 723-756. DOI:10.1093/sf/sot092.

This study looks at women's retention and attrition in the STEM fields in comparison to women in other professional fields. What the researchers find is that women in STEM "do not react positively to increasing job satisfaction, job tenure and advancing age, suggesting that climate issues or lack of "fit" between worker and job persist for longer periods of time in STEM careers [...] This helps explain the widening retention deficit that STEM women experience over time relative to professional women." Interestingly, the researchers also find that the more education women in STEM receive, the more likely they will leave STEM proving that the environment for advanced-degree holders may be more isolating than those with just bachelor's degrees. This could relate to that idea of the "Onlys" that was referenced in Women in the Workplace or the idea of tokenism in this piece. The authors note that "Whatever the origin of these effects, the fact that advanced training, increasing job tenure, job satisfaction, and aging do not deepen commitment to STEM fields as they do for most other workers in most other fields is particularly troubling." In addition, the authors found that issues around family-work life balance may affect women in STEM more deeply than other professional women and that "the biggest problem in STEM retention occur so early in STEM careers." This is also similar to the idea of the "broken-rung" that was highlighted in Women in the Workplace where issues begin with fewer women being hired/promoted to manager which affects the number of women in general in the field and especially the women qualified to rise to leadership roles. The study also notes that because of the lack of women in leadership position in STEM, women entering the field are more susceptible to feeling isolated and having to put up with gender-conservative men and structures. It is important to note that the retention of women in STEM is due to those women switching out of STEM not leaving the labor force entirely.

I think that this article is unique in that it compares women in STEM with women in other fields to get a sense of how women in STEM may react differently to various variables rather than compare women in the same field to men. I think its findings are particularly important when thinking about how the culture of STEM working environments does not appeal to women long term and it's not that women leave the labor force it's just that they are leaving STEM.

28. Gilbert, J. A.; Ivancevich, J. M., Valuing Diverity: A Tale of Two Organziations. The Academy of Management Executive 2000, 14 (1), 93-105.

This study compares two organizations in their quest to promote diversity: one that has implemented sweeping changes to their organizational structure and the other that has flaccidly expressed their valuing of diversity but has taken minimal steps to engendering true change. To begin, the authors note that one of the biggest differences between these two organizations and successful versus unsuccessful attempts in general, starts with the CEO or head of the company. 
In this case, the CEO of the first company, Multicultural Organization, altered the mission statement and company goals to incorporate promoting diversity which had positive ripple effects for the way the company approached diversification efforts. Additionally, the authors note that the standardization of organizational policy for all branches that was supported and enforced by top leaders influenced the way employees reacted to diversification efforts. This could be seen in the operationalization of human resources. For example, a team of managers was created to identify areas where the company could improve, the company set out to equalize pay among all employees at the same level, and the company committed to having women and people of color occupy one third of all supervisory positions over the course of 9 years. To satisfy this commitment, members of the organization went to conferences geared towards minority workers and attended career fairs at universities with high numbers of minority students. Additionally, the company conducted annual cultural audits and created a vice president for diversity position, hosted an annual diversity conference highlighting best practices, and distributed educational diversity material. An Equality Council made up of company employees was also created and met monthly to discuss barriers to promoting diversity in the workforce. The goal of this group was to help include employees in creating organizational policies. Some suggestions the group came up with included having an anonymous box dedicated to diversity issues where employees could voice their concerns and complaints, "preparing guidelines to be utilized for first-line supervisors when appraising employees in the equality area," and integrating articles about diversity into the company newsletter. This group also created an employee survey, which was used to inform supervisors and diversification efforts. The authors highlight how efforts to include employees created a sense of ownership at all levels and "repeated exposure helped to promote the attitude that diversity was a normal." The authors stress that "efforts to address managing diversity must be supported by profound changes reflected in day-to-day operation," and suggest analyzing "educational programs, human resource practices, change in philosophy, and CEO commitment" as ways to achieve sweeping changes. In terms of measuring the effectiveness of diversity efforts, the authors suggest monitoring "employee turnover, job satisfaction, and positive community relations communicated by our own employees," as some of the quantifiable ways managers can make assessments. The authors conclude this paper by suggesting that companies construct a plan to achieve diversity, develop an ongoing education program, and develop hard measures. Additionally, managers must focus on areas related to "communication, compensation, recruiting, committee membership, promotions, advertising, and family and work-life initiatives."

29. Green, T. K.; Kalev, A., Discrimination-reducing Measures at the Relational Level. Hastings Law Journal 2007, 59 (6), 1435-1462.

This article analyzes discrimination reducing measures at the relational level meaning "social interactions and relations at work that operate to reinforce stereotypes and bias." The authors begin by noting that "formalization of personnel decision making, accountability, diversity training, attention to demographics, even formal networking and mentoring programs" target individuals and they tend to miss the "interactional, relational level of discrimination." As confirmed in the research, diversity teams or committees may be more 
successful in reducing inequality by creating structures that establish accountability and responsibility thereby integrating equity efforts into daily practice. In contrast, the notion that increased exposure to members of minority groups reduces bias, keeps measures at the individual level. However, having a diverse group involved in decision making processes may have longer term effects. For example, a diverse panel of interviewers may reduce bias on the interviewee and ultimately the entire hiring process. The authors also discuss formalization and transparency and note that stereotypical thinking is not necessarily eliminated by developing and formalizing criteria for decision making but it may reduce biases and stereotypes of the decision maker. Finally, while the researchers acknowledge that mentoring and network can be very useful, these measures still fall short of addressing relational issues and do not "disrupt the existing day-to-day relationships between members of different groups." In thinking about ways to revise organizational relations, the argument for creating a more collaborative work environment is presented. For one, it is clear that demographic differences are less apparent in more collaborative organizations that stray from traditional hierarchical structures. In these work environments, cooperative interdependence is support and encouraged reducing status differentials that often cut across race and gender lines. Furthermore, in organizations that encourage network-based practices where those in lower level jobs interact and work with those in higher level jobs, discrimination at the relational level is reduced and women's and minorities' career outcomes improve.

\section{Heilman, M. E., Description And Prescription: How Gender Stereotypes Prevent Women's Ascent Up the Organizational Ladder. Journal of Social Issues 2001, 57 (4), 657-674.}

This article discusses how gender bias and stereotypic descriptions and prescriptions, produce biased evaluations. For women, the notion that they should behave communally juxtaposes the agentic behavior associated with managerial roles. This conflict elicits gender bias from evaluators by influencing perceived lack of fit, which greatly affects performance expectations and thus the evaluation processes. The author references research demonstrating gender bias in hiring practices by observing identical female and male applicants and the proclivity for men to be perceived as more likely to succeed based on nothing more than their gender. In addition to the biases arising from stereotypic attitudes, the author notes that women's work is often seen as inferior and women's successes are "undervalued compared to those of men." The article goes on to discuss organizational conditions that facilitate this culture which include ambiguity in evaluation criteria and lack of structure in the evaluation process. The author argues that "the more inference is required to draw implications from performance information, the more likely bias will enter into evaluative judgements." Similarly, if the system for evaluation is not structured, "the use of expectation's as a filter for reality" is inherently encouraged. This article draws similar conclusions to other studies and reports reviewed that find that women are derogated and viewed unfavorably if they are seen as competent and agentic. The author concludes by highlighting that gender stereotypes found at the root of workplace culture limit women's upward mobility and that ambiguity about a woman's competence results in being viewed as incompetent; additionally, if a woman's competence is unquestionable, "they are apt to be socially rejected." 
31. Heilman, M. E.; Wallen, A. S.; Fuchs, D.; Tamkins, M. M., Penalties for Success: Reactions to Women Who Succeed at Male Gender-Typed Tasks. Journal for Applied Psychology 2004, 89 (3), 416-427.

In this study, the researchers conducted 3 separate studies to explore reactions to women's success in male gendered-type jobs. They found that female success can create social problems for women and lead to negative evaluations. Seeing as evaluations are closely aligned to salary and job opportunities, this poses a serious threat to women in general. However, the researchers found that it is not success in and of itself that negatively affects women-it's success in roles that defy gender-stereotypic norms. They conclude that while successful women may not be labeled as incompetent, the social implications can be deleterious and damaging in other ways.

The findings of this study reinforce others that discuss female success and the challenges that come with it.

32. Hill, C.; Corbett, C.; St. Rose, A. Why So Few? Women in Science, Technology, Engineering and Mathematics; Washington, DC, 2010.

This report thoroughly examines the underrepresentation of women in STEM focusing on 8 different societal and environmental factors causing the dearth of women in the field. Ranging from the messages girls receive in elementary school about their scientific and mathematical capabilities to the lack of support many professional female scientists feel, this report explains the many ways in which women are prevented from entering and advancing in STEM. The report is divided into 10 chapters which explore topics such as beliefs about intelligence, stereotypes, self-assessment, the college student experience, university and college faculty, implicit bias, and workplace bias. In Chapter 2, the notion of a growth mindset versus a fixed mindset can lead students to believe that excelling in STEM fields takes practice and learned skills as opposed to simply being gifted, which can lead to more resources being offered to both female and male students at equal rates. This relates to the idea presented in Chapter 4 where the authors discuss self-assessment and how women hold themselves to a higher standard than males in "masculine" fields. The report notes that "women believe that they must achieve at exceptionally high levels in math and science to be successful STEM professionals. If women hold themselves to a higher standard than men do, fewer women than men of equal ability will assess themselves as being good at math and science and aspire to science and engineering careers." Not only if women are holding themselves to higher standards but they are not taught that being "good" in STEM simply takes practice, then this may lead to higher attrition. The report goes on to discuss the college student experience in Chapter 6 and how recruitment, admissions, departments and faculty all play a role in female success. The report notes how curriculums may support one gender more than another. For example, it writes "the rub for women in computer science is that the dominant computer science culture does not venerate balance of multiple interests. Instead the singular and obsessive interest in computing that is common among men is assumed to be the road to success in computing. This model shapes the assumptions of who will succeed and who 'belongs' in the discipline." In addition, having a diverse faculty is crucial. Interestingly, the 
report highlighted how HBCUs have created a path toward a physics degree for students who didn't necessarily come with all of the academic knowledge needed to attain a physics degree right out of high school. This reinforces the notion that there should be pathways versus pipelines and provides more opportunities for those who have not historically succeeded using the conventional method of attaining a degree in science. It is important to note that the report mention that "young African American women express more interest in STEM fields than do young white women [...] The number of African American women in STEM remains low, however, suggesting that other barriers are important for this community."

In Chapter 7, the report discusses faculty in academe and the reasons for the lack of gender diversity. The authors note that female STEM faculty felt that they did not feel as if they truly fit or belonged in their department. The isolation many women felt from being the only or one of a few women on faculty resulted in more women leaving due to feeling excluded from social gatherings or professional and career development opportunities. In addition, the culture of the department didn't support family-work balance, which disproportionately affects female professionals, and both men and women reported child-care on campus as lacking. Many women noted that mentoring helped address these feelings of marginalization. Chapter 8 and 9 focused on bias both implicit and in the workplace. Bias in both evaluation and in advancing professionally affect women in much larger proportions than men. The report notes the challenge with being both competent and well-liked which was discussed in Being in Advocate for Others, Unless You Are a Man: Backlash Against Gender-Atypical Male Job Candidates. In addition, bias can present itself in peer reviews. The report noted that female postdoc applications have to be more productive than their male counterparts to receive the same peer review score. The report writes, "systematic underrating of female applicants could help explain the lower success rate of female scientists in achieving high academic rank compared with their male counterparts." The report ends with several recommendations for educators, department heads, and parents.

33. Hofmann, Y. E., Strobel, M. (2020) Transparency Goes A Long Way: Information Transparency and its Effect on Job Satisfaction and Turnover Intentions of the Professoriate. Journal of Business Economics, 90, 713-732. DOI: 10.1007/s11573-02000984-0

In this study, Hofmann and Strobel (2020) research how transparency might affect faculty members and their job attitudes. Concentrating on how university professor's experience disclosure of information and how their experiences with a more or less transparent working environment influence their satisfaction with working conditions and turnover intentions, the researchers conclude that there is a positive relationship between transparency and job satisfaction and a negative relationship between transparency and intent to leave. Based on the answers given by 1600 professors, the researchers findings suggest that "information disclosure-specifically, the department's openness about structures, processes, and resources - is not only a relevant factor for how satisfied professors are with their working conditions but may also result in a reduction of professors' intentions to leave." 


\section{Holvino, E.; Ferdman, B. M.; Merrill-Sands, D., Creating and Sustaining Diversity and}

Inclusion in Organizations: Strategies and Approaches. Blackwell Publishing 2004.

This chapter discusses the Model of Multicultural Organizational Development (MCOD) framework developed by Holvino (1998). The framework describes 6 phases that organizations must go through to go from being monocultural to multicultural where diversity is celebrated and fully integrated. These include the exclusionary stage, the passive club stage, compliance, the positive action stage, the redefining stage, and finally the multicultural or inclusive and diverse stage. The first phase describes an organization that is intentionally exclusive and supportive of one dominant group. In each subsequent phase the organization becomes less and less exclusionary and more accepting of differences and committed to developing systems that support all members of every group. In other words, the final stage is one where there is "equality, justice, and full participation at both the group and individual levels, so that members of different groups not only have equal access to opportunities, decision-making, and positions of power, but also are actively sought out because of their differences." It becomes clear, then, that while diversity is an obvious tenet of this realization, so too is inclusion, which is noted as being "fundamental for incorporating equality and truly sharing power across a range of groups and their members." Together, these two elements, diversity and inclusion, require allocating resources to shifting organizational structures and helping members internalize this philosophy. To do this, diversity initiatives must address three organizational layers: structure, culture, and behavior. Structural interventions target policies, practices, and structures that either positively or negatively impact diversity efforts. These include recruitment practices, equal pay and benefits, or policies on family balance. Additionally, providing access to decision making and organizational power can reduce stereotyping, prejudice and dynamics of tokenism. Cultural interventions, known as being one of the more difficult parts of diversity initiatives, work to change basic assumptions, values or beliefs. It is noted that training interventions, while they are popular, do not change organizational culture - the best way, is to "identify informal practices and beliefs that make up culture, to analyze their consequences, and then introduce small experiments designed to change everyday practices." One way to do this is through cultural audits or employee surveys. Lastly, behavioral interventions may take the form of coaching or team building but the authors caution against focusing too much on 'fixing the people' or 'equipping the minorities' at the expense of analyzing systemic structures and cultural factors that influence the workplace.

In order to support organizational development, a 5-step approach is introduced. The steps include preparing for an initiative, assessing the needs related to diversity, vision, and goal, implementing the interventions, monitoring the interventions, and evaluation. The authors also suggest developing a strategic plan that guides the initiative and defines goals for management, provides structure, clarity, and accountability and links the change effort to the gains that will be derived from the initiative. Accountability and evaluation are crucial elements of diversity initiatives; areas to evaluate could be changes in individual attitudes or the level of satisfaction of members from different groups. Additionally, the authors stress the importance of visible 
leadership from the top and middle managers. To conclude, tactical considerations for initiative sustainability are reviewed including eliciting the help of both internal change agents and external consultants, and common diversity traps that organizations fall into such as assuming short term training will be enough and/or isolating efforts in just one department or under one person.

35. Huang, J.; Gates, J. G.; Sinatra, R.; Barabasi, A.-L., Historical Comparisons of Gender Inequality in Scientific Careers Across Countries and Disciplines. PNAS 2020, 117 (9), 4609-4616.

This research focuses on increasing gender differences in total productivity and the impact of academic careers across STEM fields simultaneous to the rise in the number of women entering the various fields. In order to effectively demonstrate their findings, the researchers focused on over 1.5 million researchers, $\sim 1 / 4$ female and $3 / 4$ male, from 83 countries and across 13 major disciplines with publications spanning over 60 years. They found that "men and women publish a comparable number of papers per year and have equivalent career-wise impact for the same total number of publications." However, other analyses revealed that "the productivity and impact of gender differences may have more to do with publishing career lengths and dropout rates." Based on the numbers, it appears that women are at much higher risk of to leave academia than their male counterparts. While the authors don't necessarily ponder why this occurs, they conclude that it is important to reframe the conversation about female academics and look to administrative policies to help retain female employees instead of just focusing on recruiting junior scientists. They also take care to note that their findings on dropout rates don't account for the whole picture and there may be other factors such as perception of talent to resource allocation that may be a factor in the gender gap.

45. Hunt, J. Why Do Women Leave Science and Engineering? ILR Review 2016, 69 (1), 199226.

This study focuses on the gender differences in exit rates in engineering. The researcher compared women in engineering to women working in other fields and found that women leave engineering at higher rates than women employed in other occupations. The researcher also found that one of the primary reasons for dissatisfaction was pay and promotion opportunities. Interestingly, the researcher found that in engineering, the gap between men and women leaving is small to start but expands over 20 years.

36. Ibarra, H., Race, Opportunity, and Diversity of Social Circles in Managerial Networks. The Academy of Management Journal 1995, 38 (3), 673-703.

This study focuses on the differences in both the perceptions and demographics of minority and White employees' network groups. Network groups are defined here as a set of contacts an employee relies on for both career and social support. The utility of network groups is seen as both the potential access to information and resources provided by a diverse set of contacts and the status of the contacts in the relevant hierarchy. However, it is also important to 
note that in addition to these utilitarian components, there is a psychosocial element, or the proximity of relationships in the network, that determines whether or not a contact will share beneficial information with one individual over another. The research indicates that homophily often strengthens interpersonal bonds and cross-race relationships tend to be weaker. This poses a disadvantage to minority employees who "have a much smaller set of same-race others with whom to have informal interaction" and must work to relate to both the dominant culture where job-related resources may be shared and minority networks where employees can receive psychosocial support. Therefore, "minorities with greater potential for advancement will develop a mix of same-race and cross-race relationships, in contrast to both their white and less mobile minority counterparts, who are expected to have networks dominated by ties within the majority group." However, if networks provide dissimilar benefits to employees from different ethnic groups, it is possible that minority employees may not place as much importance on high status as White employees. This may lead to a gap in who gets access to information and resources. The results of the study confirmed that Black managers must develop relationships with White sponsors in order to be successful, however, they may not rely on them for psychosocial support. Additionally, Whites viewed a range in their networks more positively than minorities indicating that minorities feel as though they are not receiving all that they need from having a diverse set of contacts.

26. Johnson, W. B.; Smith, D. G. How Men can become better allies to women. Harvard Business Review. 2018.

This article describes tangible ways men can be better allies to women and references studies that found that when men are engaged in gender inclusion programs, $96 \%$ of organizations see progress in narrowing the gender gap. The authors stress that gender equity efforts are often misplaced onto gender initiatives that focus on women, rather than men. Similar to the article Be an Advocate for Others, the authors note that sexism hurts everyone, and it is important to include men in the process of dismantling biases and exclusionary behavior. The article also notes how men may actually face backlash for promoting diversity. However, the authors suggest that "the more positive interaction men have with women in professional settings, the less prejudice and exclusion they tend to demonstrate." Including men in initiatives or conferences to increase gender equity requires a certain technique so the focus doesn't stray from female empowerment but nevertheless, priming men for being allies is an important way to break down barriers.

37. Kalev, A., Dobbin, F., Kelly, E. (2006). Best Practices or Best Guesses? Assessing the Efficacy of Corporate Affirmative Action and Diversity Policies. American Sociological Review, 71, 589-617

In this study, the researchers analyze diversity by race and gender in management positions of over 700 private sector work organizations between 1971-2000. The researchers focused on three types of approaches to promoting diversity and find that the most effectives practices involve "those that establish organizational responsibility: affirmative action plans, diversity staff, and diversity task forces." In contrast, the least effective programs for increasing 
diversity are those that focus on quelling managerial bias through education and feedback. Additionally, the researchers find that attempts to reduce social isolation among women and African American through networking and mentoring programs are not as promising as the programs that establish organizational responsibility listed above.

38. Kidder, D. L.; Lankau, M.; Chrobot-Mason, D.; Mollica, K.; Friedman, R. A., Backlash Toward Diversity Initiatives; Examing the Impact of Diversity Program Justification, Personal, and Group Outcomes. International Journal of Conflict Management 2004, 15 (1), 77-102.

This study focuses on White backlash against minority employees when companies implement diversity initiatives. It is noted that the negative attitudes White employees have towards the preferential treatment of minority employees hinges on two assumptions: "that preferential treatment leads to the hiring of unqualified minorities" and "that workplace discrimination is no longer a problem in the United States." Not only does this indicate a lack of awareness but it proves that the way equity is discussed is remiss and incomplete. The researchers explain that there is a difference in perception between diversity management and affirmative action. Whereas with affirmative action White employees see themselves as standing to lose, with diversity management, companies promote diversity initiatives as a strategic tool to enhance efficiency and productivity leading the corporation to gain, as a whole. It is important to point out that the reactions of White employees to these different initiatives stems from both the perceived personal and group outcomes from promoting diversity. These responses may be influenced and/or mitigated by personalization and positive orientations towards other ethnic groups, and by the gender of the respondent. The researchers test several hypotheses measuring the strength of backlash considering different variables including whether or not management offers a reactive (affirmative actions) versus competitive (diversity management) business justification, if personal outcome is unfavorable, if group outcome is unfavorable, if White respondents have personal connections to other ethnic groups, and how gender affects respondents' response. The results of the study showed that "outcome favorability had the largest impact on negative emotions, program justification had the most significant effect on attitude toward the program, group level outcome favorability had the greatest influence on perceptions of unfairness of the selection procedures, and personal outcome favorability had the most significant effect on organizational commitment." The researchers conclude by offering suggestions for managers working to fortify or implement diversity management in their places of employment. These include, using a pro-business justification for diversity, understanding employees' views on diversity to aid in the development of awareness trainings and educational materials, and providing managers resources to effectively manage diverse teams. Additionally, the authors suggest implementing and clearly communicating standards for performance and qualifications for promotions, and creating an open environment where supervisors honestly communicate with their employees about promotional decisions to alleviate backlash. 
39. Lichtenstein, G.; Chen, H.; Smith, K.; Maldonado, T., Retention and Peristence of Women and Minorities Along the Engineering Pathway in the United States. Cambridge University Press: Cambridge, 2014.

This report focuses on the persistence and retention of women and URM in STEM, and more specifically in engineering. The authors differentiate between persistence and retention intentionally because it is posited that using them interchangeably "glosses over significant challenges faced by women and people of color navigating STEM pathways." In this case, retention is defined as completing a phase in one's STEM career while persistence refers to making the transition from one phase to the next and continuing in STEM. The authors fracture the different developmental stages of one's life into 3 eras: high school to college, the college experience, and continuing education and the workforce. During the postgraduate phase, the proportion of women and minorities drops sharply and marriage and childbearing results in decreased rates of employment for women; the inverse is true for men-marriage and families result in an increase in employment. In terms of retention, the authors discuss in detail the "chilly climate" effect where cultural practices include "negative interpersonal relations, subtle and overt denigration of skills, attribution of attainment to affirmative action policies, avoidance of eye con- tact, favoritism toward male and majority students, sexual harassment, and, in the workplace, a dearth of opportunities to advance, failure to be recognized for contributions, and wage disparities." Additionally, the authors note that chilly climate has been cited as a reason for attrition in engineering. In order to promote retention and persistence and mitigate the deleterious effects of chilly climate, several strategies are suggested including "providing hands-on undergraduate and graduate research experiences, aligning new programs with successful existing ones, extending the "personal touch" with plenty of mentoring and attention to individual needs, providing incentives to laboratory researchers to broaden participation by women and underrepresented minorities, and having personnel dedicated to tracking students in academic programs."

40. Lyness, K. S.; Judiesch, M. K., Are Women More Likely to be Heard or Promoted Into Managment Positions? Journal of Vocational Behavior 1999, 54 (1), 158-173.

This study observes the differences in hiring and promotional practices for women in management positions. The researchers found that women are more likely to be promoted versus hired as external candidates. This has serious implications for women because organizations look to external candidates to hire into middle and higher-level management positions rather than promote internal employees. If companies are looking outside of their organizations to fill higher level positions, women may be overlooked. The researchers noted that male recruiters may find and recruit higher numbers of male candidates because of social similarity. The networks that men are a part of may also alert them to job opportunities that women are not privy to. Promotion versus hiring has resulted in less women at the top and more women in middle and lower positions because of the way that organizational structures are changing.

41. Massachusetts Institute of Technology (1999). A Study on the Status of Women Faculty in Science at MIT. 
This report details the findings of a Committee that analyzed the status of women faculty in the six departments in the School of Science at MIT. The Committee found that while junior women felt well supported, tenured female faculty often felt marginalized and excluded from significant roles in their departments. Thus, it was concluded that feelings of marginalization increased as women progressed in their careers. Additionally, the report outlines how "marginalization was often accompanied by differences in salary, space, awards, resources, and response to outside offers between men and women faculty with women receiving less despite professional accomplishments equal to those of their male colleagues." Even more concerning was that this trend had not changed significantly over the last one to two decades, which was evidenced by the stagnant percentage of female faculty over the analyzed time period. Several recommendations were made by the Committee including reforming family-work culture for junior women faculty and increasing the number of overall female faculty. The latter of the recommendations extended to underrepresented minorities, as well and the School of Science pledged to try and hire more professors who identified as a URM.

42. Nielsen, M. W.; Alegria, S.; Borjeson, L.; Etzkowitz, H.; Falk-Krzesinski, H. J.; Joshi, A.; Leahey, E.; Smith-Doerr, L.; Woolley, A. W.; Schiebinger, L., Gender Diversity Leads to Better Science PNAS 2017, 114 (8), 1740-1742.

This short piece argues that increased diversity leads to more innovative problem solving and could lead to more scientific discoveries. The general differences in gender characteristics that men and women may bring to a group creates a holistic and multifaceted approach to a problem and consequently, a solution. The authors argue that organizations must cultivate a positive climate for gender diversity. It has been shown that women tend to excel in environments where there is cross-job communication and nonhierarchical structures. Additionally, researchers have posited that a culture that encourages all employees to express themselves and gender identity can lead to more inclusivity. Lastly, the authors note that in organizations where women and underrepresented minorities have reached a critical mass there is less stereotyping, more involvement in decision making and teamwork, and higher levels of support. With effective leadership that is committed to reducing bias while increasing employee satisfaction, it is possible that the turnover rates for female scientists will decrease and team diversity will be retained.

43. Nishii, L. H., The Benefits of Climate for Inclusion for Gender-Diverse Groups. Academy of Management Journal 2013, 50 (6), 1754-1774.

This study focuses on inclusive work environments, which are characterized as "a collective commitment to integrating diverse cultural identities as a source of insight and skill," as a means to decreasing conflict and increasing gender equality. Incongruent to 'plural' organizations--bodies that attempt to increase diversity without changing the current cultural norms rather expecting nontraditional employees to assimilate-- inclusive environments "alter the socio-relational context within which heterogenous individuals interact." This occurs by ensuring that people "(a) are of approximately equal status; (b) have opportunities to get to know each other in more personal ways, establish cross-cutting ties, and rely less on stereotypes; and 
(c) work together across roles, levels, and demo- graphic boundaries to solve shared problems through participative decision making." Reiterating the findings of Kalev and Dobbin (2006), the researcher notes that if diversity programs solely focus on the marginalized groups, resentment and backlash can fester and unintended negative consequences can occur. In order to move to a more inclusive environment, it is suggested that fairly implemented employment practices must be instituted to reduce bias, along with working to integrate differences across multiple identities. This helps foster more authentic relationships as employees are encouraged to be themselves and more complex perceptions of others can develop leading to the deconstruction of stereotypic confirmations. Additionally, it is important to include employees in decision making processes in an effort to support commitment and attachment to the workplace. The purpose of trying to create inclusive environments is to invalidate social hierarchies that fuel inequality, bias, and conflict. Furthermore, the researcher notes that "promoting norms for collaboration and/or openness may be ineffective because they focus only on conflict itself, and not also on the more general interpersonal context within which the conflicting parties are embedded." In contrast, inclusive environments foster sympathy and conflicts are seen positively; a learning experience that supports growth and ultimately supports unit morale. The researcher ends with practical implications of this study which include careful monitoring of "HR outcomes and employee perceptions of the fairness of employment practices to reveal biases that may stand in the way of making meaningful improvements to the other two dimensions." Additionally, the researcher urges organizations to minimize conflict by "minimizing structural inequalities, norms for assimilation, and exclusionary decision-making processes."

44. Picciano, M. Why You Need to Upgrade your Accountability System MMI Inc. [Online]. https://www.matrixmanagementinstitute.com/blog/why-you-need-upgrade-youraccountability-system/ (accessed March 5, 2021).

This short article discusses why organizations should consider shifting towards a culture of shared accountability rather than relying on individual performance. The author writes that by focusing on the individual, the entire team may suffer because "most accountability systems rate employees for their personal contributions, which encourages people to focus on their job responsibilities at the expense of the larger team." Furthermore, this individualistic perspective prevents employees from seeing how their actions fit into the larger organizational picture and distracts individuals from engaging in collaborative efforts. Rather than emphasizing accountability after something has gone wrong, the author recommends that leaders make shared accountability a clear priority from the beginning. For example, the author writes "rather than assign tasks based on an approved plan, leaders should invite team members to build the plan with them." By being inclusive, team members become more away of how they contribute to the shared vision. This collaborative process ensures commitment from employees and fosters an understanding of who is accountable for which tasks and when. In this way, the leader's role also shifts to becoming more of a facilitator; they are no longer seen as having all of the right answers, rather their role is to encourage everyone to participate. The author argues that in order to build shared accountability, communication, cooperation, and collaboration are key. By investing in this new system, organizations will be able to improve project management and 
strategy execution while engaging employees and taking full advantage of their human resources potential.

45. Pickett, M., I Want What My Male Colleague Has, and That Will Cost a Few Million Dollars. New York Times Magazine 4/18/2019, 2019.

This article discusses the prestigious Salk Institute and the gender disparities that exist between senior male and female scientists. Told through the stories of 4 faculty members, it discusses how women scientists were given smaller labs, less funding, and were not invited to speak at conferences. It also touched on sexual harassment suits that were filed and settled, although the Institute was dismissive and did not acknowledge that any infractions may have taken place. A notable piece from the article quoted one of the senior women scientists reflecting on how there are men who want gender equality for women but their efforts are usually focused on younger women because it costs less than fighting for equality for women in senior positions. It also discusses the statistics regarding women in science in general and noted that the number of women drops off at every increasing level of rank in academic science. The author mentions women wanting to start families, as well, so there may be an opportunity to create more flexibility around expectations in an effort to be more equitable. This is all very important because as the article quoted from a letter that was published by many esteemed scientists, the next generation is watching and if women see that they are not being appreciated or there aren't opportunities for career advancement, that sends a powerful message.

\section{Quinn, R. E. (2015). The Positive Organization: Breaking Free from Conventional} Cultures, Constraints, and Beliefs. Berrett-Koehler Publishers, Incorporated.

In his book, Quinn focuses on how to create positive work environments where people feel connected and engaged, and as though they can reach their full potential. Quinn contends that it is important to break free from the more top-down, hierarchical management model where people are driven by self-interest and fear. Instead, he suggests that organizations move towards a form of management that includes everyone and supports a fluid network of people. Throughout the book, Quinn provides several suggestions for leaders on specific actions they can take to create a more positive organizational culture which includes helping people find purpose, have meaningful conversations, and see new possibilities. Quinn also provides the Positive Organization Generator, which is a tool that is meant to aid in the process of conceptualizing and implementing the practices that will help reform an organization based on its specific needs and desires.

47. Rock, D.; Grant, H.; Grey, J., Diverse Teams Feel Less Comfortable - And That's Why They Perform Better. Harvard Business Review 2016.

This article discusses the relationship between the discomfort that arises from working on diverse teams and its influence on enhanced performance outcomes. Similar to the article How 
Diversity Makes Us Smarter, the authors confirmed that people on homogeneous teams feel more comfortable, collaborate more smoothly, and understand each other better, giving the impression that progress is being made. However, according to a 2009 study of fraternity and sorority members, including an outsider in a group problem solving experiment doubled the chances of a team reaching the correct solution. As the authors note, "the work felt harder, but the outcomes were better." The authors go on to connect this paradox to a common bias called the fluency heuristic which describes our preferences for information "that is processed more easily, or fluently" thus "judging it to be truer or more beautiful." Looking back to the previous study, it becomes clear that it is precisely the difficulty that arises out of interacting with diverse team members that leads to more positive outcomes because while engaging with dissimilar opinions may seem tedious, it leads to more creative thinking and growth. The authors also note another element at play: the erroneous assumption that working on diverse teams will lead to more conflict and less productivity. They warn against the deleterious effects of this line of thinking on hiring and the ways in which leaders create teams and encourage collaboration. The authors write that "without realizing it, [leaders] may be reluctant to add diversity to a team or to assign colleagues with different backgrounds to work together, in response to an (overblown) fear of the tension and difficulty that could ensue." In response, the authors encourage leaders to recognize that the unfamiliarity and discomfort that comes with diversity is an important part of creativity and deep thinking that will positively affect everyone, including the organization.

48. Schneider, A. K., Negotiating While Female. Southern Methodist Universtiy Law Review 2018, 70 (3), 697-719.

This article is primarily concerned with debunking the idea that women's lack of negotiation skills is an attributing factor to the gender wage gap. The author breaks down her argument into three myths: Women don't negotiate, Women shouldn't negotiate because of backlash, and Women can't negotiate. She discusses how the findings of many studies are inaccurate because they do not take age or context into consideration. Additionally, she notes that socialization affects the way that women are taught to think about their self-worth, which in turn affects how they think about negotiating. However, the author discusses how once women are taught to negotiate, there is very little difference between genders. Schneider also considers how women are perceived when they do negotiate. Biases about how women should behave can lead to backlash when women are seen as assertive or confident and women in leadership are often forced to decide between being "likeable or competent." These barriers could influence women advocating for higher pay or vying for promotions. The author ends with addressing what individual negotiators can do, such as working within the stereotype or breaking the stereotype, and what companies can do. She suggests that if a workplace is particularly gender unbalanced, creating more transparency around about salaries and benefits and praising women for being assertive can lead to more positive outcomes. 
49. Smith-Doerr, L.; Alegria, S.; Sacco, T., How Diversity Matters in The US Science and Engineering Workforce: A Critical Review Considering Integration in Teams, Fields, and Organizational Contexts. Engaging Science, Technology and Society 2017, 3, 139-153.

In this literature review, the authors explore why some studies show that diversity of STEM teams leads to more positive results (i.e. more creativity, productivity, etc.) and others do not. The authors detail the difference between simply increasing numbers of women and minorities and actually integrating these marginalized groups in an effort to foster equitable work environments. They find that when organizational contexts include positive environments, then the outcomes of diversity are better and note that "part of the confusion about whether diversity matters stems from conflating diversity and integration and failing to look beyond demographic profiles at how teams actually work (or fail to work) together." This review culminates with suggestions for policy makers, academics, and business managers.

50. Stockard, J.; Green, J.; Lewis, P.; Richmond, G. L., Promoting Gender Equity in Academic Departments: A Study of Department Heads in Top-Ranked Chemistry Departments. Journal of Women and Minorities in Science and Engineering 2008, 14, 127.

This paper focuses on the workshop described in JWMSE 2011 and JChemEd 2011. It examines how a workshop given to department heads from 69 academic chemistry departments influenced and altered perceptions around barriers women face in the chemistry field and what departments can do to increase diversity. Through a pre and post workshop survey, the researchers found that before participating in the workshop, department heads felt that the factors limiting their ability to hire women were beyond their control. After engaging in this workshop, participants felt that in contrast to the lack of diversity being due to exogenous reasons, respondents felt that their department faculty members were not committed to hiring women. Thus, the workshop proved that planned intervention can result in significant changes to perceptions about gender equity. The researchers highlighted three factors that could have led to its success: the problem of underrepresentation can be easily recognized and can be addressed without changes that would involve the graduate pipeline/supply, targeting department chairs may have been particularly useful seeing as they are exposed to women students and know the availability of women chemists who would be great faculty members, and lastly, the actual characteristics of the workshop may have initiated the change in thought patterns.

51. Sturm, S., The architecture of inclusion: Advancing Workplace Equity in Higher Education. Harvard Journal of Law and Gender 2006, 29 (2; Summer 2006), 247-334.

This article focuses on how universities can achieve inclusive environments by addressing structural issues leading to racial and gender under-participation. It builds on the idea that "workplace equity is achieved by connecting inclusiveness to core institutional values and practices" (249). Sturm discusses three related ideas in advancing workplace equity: institutional 
citizenship, organizational catalysts, and institutional intermediaries. Institutional citizenship refers to the practice of "identifying and removing institutional barriers that arbitrarily thwart the participation of women, people of color, and other excluded groups. Taking steps to eliminate those institutional barriers often advances the more general goal of enabling full and fair participation" (250). Organizational catalysts are people with "knowledge, influence, and credibility" who are placed in positions where they can influence areas where gender and racial biases are endemic. Institutional intermediaries are public or quasi-public organizations that act as capacity builders to provide incentives, accountability and knowledge without the fear of legal reprisal. Using the University of Michigan and its relationship to the National Science Foundation and the ADVANCE program - a foundation wide effort to increase the participation and advancement of women in academic science and engineering careers-Sturm analyzes the outcomes of UM's implementation of initiatives to overcome inequities and encourage "women's participation and advancement as faculty" (252). These initiatives focus on changing the structural paradigm and resulted in positive lasting changes.

52. Sturm, S., The architecture of inclusion: Interdisciplinary Insights on Pursuing Institutional Citizenship. Harvard Journal of Law and Gender 2007, 30, 409-424.

Using the architectural metaphor, Sturm focuses on 3 main ideas for developing and sustaining efforts to address structural inequality: institutional citizenship, organizational catalyst, and institutional intermediaries. She defines institutional citizenship as creating conditions for URM and women to be able to fully participate and realize their full potential within the institution. Sturm notes that diversity is a group phenomenon and encourages hiring agents to pursue their task by focusing on hires as a group instead of as individuals. In terms of women in science, Sturm points out that institutional citizenship must go beyond the workplace to actually defining the culture of science. The second feature of this framework is including an organizational catalyst who is an individual that leverages their knowledge, networks, and forms of accountability to mobilize change. They are unique in that they span different boundaries which enables them to cut across silos and bring together people from different institutional locations who would otherwise not connect. It is important to note that "catalysts are not defined by their marginal status but by their position as a respected member of multiple communities of practice" (419). Lastly, an institutional intermediary is a public or quasi-public organization that uses their position within communities to provide accountability and advocate for change in a meaningful way. They establish common metrics to track progress, connect networks of similar actors, and provide external accountability. Sturm takes care to note that problems concerning underrepresentation of both women and URM must be addressed simultaneously because responses designed to address gender will affect people of color and the same processes will be used for hiring, promotion, and advancement. 
53. Thomas, R.; Cooper, M.; Konar, E.; Bohrer, A.; Mohsenin, A.; Yee, L.; Krivkovich, A.; Starkova, R.; Huang, J.; Zanoschi, D. Women in the Workplace; 2019.

This report focuses on addressing women in the corporate workplace. The report finds that women are having a harder time being promoted to managerial positions early on in their careers, which affects the entire pipeline up to senior level positions. These findings contrast the Salk Institute article that found that more women occupy lower positions and are not being promoted to higher level positions. The report finds that HR is usually unaware of this gap and points to external causes for this pervasive inequity including less access to sponsorship or a lack of qualified women. The report offers several solutions for organizations to help decrease gender disparity. One particularly interesting solution is requiring diverse slates for hiring and promotions. Another is having a third party in the room when evaluators discuss candidates to screen for bias. The report references how "women are often hired and promoted based on past accomplishments while men are hired and promoted based on future potential." Having a thirdparty present during the hiring and promotion process may help decrease this phenomenon. There is also discussion about workplace culture that can foster equality and support increased employee satisfaction. Manager support and sponsorship are a huge component in achieving this so companies ought to ensure that tools are available to help managers help their employees. The report also referenced work life flexibility and how that is important to all employees. However, it is especially important for women who are more likely to have a spouse that works, as well. The notion of unconscious bias was present throughout the entire report and the authors argued that when there is only one of a certain demographic group, termed the "Onlys" it is hard to overcome this bias and those "onlys" may be treated worse. Women, for example, are more likely to be victims of microaggressions and if they are the only one in a group where they may be experiencing microaggressions more frequently or are more aware of them happening, they may be more likely to leave the workplace. This report has several case studies woven throughout of what successful companies have done to increase gender diversity and create a more welcoming culture.

54. Turban, S.; Freeman, L.; Waber, B., A Study Used Sensors to Show that Men and Women are Treated Differently at Work. Harvard Business Review 2017, 10.

This short piece posits that promotion and hiring rates at one specific company had little to do with their behavior and more to do with bias. By collecting email information and equipping staff members with little cameras, they found that there was very little difference in behavior between female and male employees but women were still not advancing at the same rates. The authors referenced a study by Iris Bohnet that showed that when hiring managers think about candidates in groups, they compare individuals by performance and less by gender. They also suggest possibly adjusting the workload as women become higher in management so that they don't have to make as many sacrifices when deciding between family and work. 
55. Wanguri, D. M., Diversity, Perceptions of Equity, and Commuicative Openness in the Workplace. The Journal of Business Communication 1996, 33 (4), 443-457.

This essay discusses equity in the workplace by focusing on communication issues that employees from marginalized communities often face. For example, the author writes that "one of the main things blacks complained about in our research was the withholding of information by white supervisors." The essay goes on to describe how Black and White employees are viewed differently with the former being given tasks where the objective is to test aptitude and the latter being expected to simply expand their knowledge and expertise. This inequitable delegation of tasks, in addition to, restricted information, lack of feedback from supervisors or coworkers and inadequate performance appraisals by supervisors or work groups are examples of 'microinequities' - covert, small, and oft unintentional aggressions that work to exclude those who are different and denigrate their confidence and feeling of belonging. In order to reverse the corrosive impact of these experiences on the workplace environment, it is noted that improving the perceived openness in superior-subordinate communication is imperative. As characterized in the essay, a good supervisor is an open and empathic listener, sensitive to the needs and feelings of subordinates, and willing to explain why policies and regulations are being enacted-just to name a few qualities. In order to accomplish this, the authors suggest mentoring as a way to help proteges "transition from outsider to insider more quickly, establish new interpersonal relationships more effortlessly, find congruence between self-evaluation and organizational evaluation of their work performance more accurately, and to resolve conflicts more readily." However, it is important to keep in mind that organizational change at the cultural, structural, and behavioral levels must be addressed in order to effectively manage diversity. If these three levels are not in synch, the benefits of mentoring will not be realized. While mentoring is a longterm solution that organizations can work towards implementing, in the short term, individual behavior can be analyzed and managers and supervisors can be encouraged to "develop an attitude of discreet and consistent communicative openness in dealing with all organizational members." The authors conclude by positing that managers must begin to reevaluate their communication behaviors and ensure that all employees have access to the same information.

56. Watson, C., Empathy and Grit - Not just Publication Records - Should be Considered in Researcher Assessment. Nature Index 2020.

Broadly, this article is about changing the evaluation paradigm in academia. The author discusses how immeasurable variables, such as resilience or perseverance, are often ignored during the hiring and promotion processes in lieu of bibliometrics. However, the most important skills an effective researcher and leader possess transcend what they have published alone, and Watson stresses that how someone conducts their work is as important as their end product. She goes on to discuss how to evaluate leadership and posits sponsorship (providing advice on grant applications or nominating a colleague for an award) as a way to demonstrate effective leadership. Finally, she notes the need to recognize subjectivity in this assessment process in order to create systems that safeguard against bias. 
57. Whittington, K. B.; Smith-Doerr, L., Women Inventors in Context: Disparities in

Patenting Across Academia and Industry. Gender and Society 2008, 22 (2), 194-218. 58.

This study focuses on the impacts of organizational setting on sex disparities in scientists' productivity in biotechnology firms by measuring patenting. The researchers note that historically, women are less likely than men to patent, but organizations that follow a network form rather than a hierarchical structure can have positive effects on women's productivity. A network form, as explained in this study, is one that relies on interorganizational relationships, has a more open-ended tone, and values collective impact over individual ascent on the hierarchical ladder. In contrast, hierarchies rely on formalized routines, resolve conflict by authority ranking, have a formal tone, and encourage individuals to focus on individual success rather than teamwork. The researchers note that many organizations that have adopted the "teamwork model" keep women in science and that "women are nearly eight times more likely to hold supervisory roles in network firms than in pharmaceutical companies." To better measure the advantages of this setting, the researchers focus on patenting because it is important to career outcomes in industry and academia. Based on statistical analyses, the results indicate that "organizations of network-based firms may provide a more equalizing environment for women scientists, at least at the level of initiation into the patenting realm." The researchers suggest that "less bureaucratic, horizontal distributions of work relations in network firms may better accommodate women scientists in the structure of science." 


\section{References:}

1. Lichtenstein, G.; Chen, H.; Smith, K.; Maldonado, T., Retention and peristence of women and minorities along the engineering pathway in the united states. Cambridge University Press: Cambridge, 2014.

2. $\quad$ Funk, C.; Parker, K. Women and men in stem often at odds over workplace equity; 2018.

3. Beasley, M. A.; Fischer, M. J., Why they leave: The impact of stereotype threat on teh attrition of women and minorities from science, math and engineering majors. Soc. Psychol. Educ. 2012, 15, 427-448.

4. $\quad$ Foundation, N. S. The state of u.S. Science and engineering; 2020.

5. Hill, C.; Corbett, C.; St. Rose, A. Why so few? Women in science, technology, engineering and mathematics; Washington, DC, 2010.

6. Rock, D.; Grant, H.; Grey, J., Diverse teams feel less comfortable - and that's why they perform better. Harvard Business Review 2016.

7. Bilimoria, D.; Joy, S.; Liang, X., Breaking barriers and creating inclusiveness: Lesons of organizational transformation to advance women faculty in academic science and engineering. Human Resourse Management 2008, 47 (3), 423-441.

8. Huang, J.; Gates, J. G.; Sinatra, R.; Barabasi, A.-L., Historical comparisons of gender inequality in scientific careers across countries and disciplines. PNAS 2020, 117 (9), 4609-4616.

9. Pickett, M., I want what my male colleague has, and taht will cost a few million dollars. New York Times Magazine 4/18/2019, 2019.

10. J., H., Why do women leave science and engineering? ILR Review 2016, 69 (1), 199-226.

11. Sturm, S., The architecture of inclusion: Interdisciplinary insights on pursuing institutional citizenship. Harvard Journal of Law and Gender 2007, 30, 409-424.

12. Coe, I. R.; Wiley, R.; Bekker, L., Organizational best practices towards gender equality in science and medicine. Lancet 2019, 393, 587-593.

13. Holvino, E.; Ferdman, B. M.; Merrill-Sands, D., Creating and sustaining diversity and inclusion in organizations: Strategies and approaches. Blackwell Publishing 2004.

14. Bilimoria, D.; Buch, K. K., The search is on: Engendering faculty diversity through more effective search and recruitment. Change: The Magazine of Higher Learning 2010, 42 (4), 27-32.

15. Lyness, K. S.; Judiesch, M. K., Are women more likely to be heard or promoted into managment positions? Journal of Vocational Behavior 1999, 54 (1), 158-173.

16. Heilman, M. E., Description and prescription: How gender stereotypes preent women's ascent up the organizational ladder. Journal of Social Issues 2001, 57 (4), 657-674.

17. Thomas, R.; Cooper, M.; Konar, E.; Bohrer, A.; Mohsenin, A.; Yee, L.; Krivkovich, A.; Starkova, R.; Huang, J.; Zanoschi, D. Women in the workplace; 2019.

18. Watson, C., Emmpathy and grit - not just publication records - should be considered in rearcher assessment. Nature Index $\mathbf{2 0 2 0 .}$ 
19. Wanguri, D. M., Diversity, perceptions of equity, and commuicative openness in the workplace. The Journal of Business Communication 1996, 33 (4), 443-457.

20. Elvira, M.; Town, R., The effects of race and worker productivity on performance evaluations. Industrial Relations 2001, 40 (4), 571-590.

21. Schneider, A. K., Negotiating while female. Southern Methodist Universtiy Law Review 2018, 70 (3), 697-719.

22. Chang, E. H.; Milkman, K. L., Improving decisions that affect gender equality in the workplace. Organizational Dynamic 2020, 49 (1).

23. Fouad, N. A.; Singh, R. Stemming the tide: Why women leave engineering; University of Wisconsin: 2011.

24. Duch, J.; Han, X.; Zeng, T.; Sales-Pardo, M.; Radicchi, F.; Otis, S.; Woodruff, T. K.; Amaral, L. A. N., The possible role of resource requirements and academic career-choice risk on gender differences in publication rate and impact. PLOS One 2013, 8 (5).

25. MIT A study on the status of women faculty in sciences at mit; 1999.

26. Cech, E. A., Ideological wage inequalities? The technical/social dualism and the gender wage gap in engeering. Social Forces 2013, 91 (4), 1147-1182.

27. Glass, J. L.; Sassler, S.; Levitte, Y.; Michelmore, K. M., What's so special about stem? A comparison of women's retention in stem and professional occupations. Soc. Forces 2013, 92 (2), 723-756.

28. Correll, S. J.; Weisshaar, K. R.; Wynn, A. T., Inside the black box of organizational life: The gendered language of performance assessment. American Sociological Review 2020, 85 (6), 1022-1050.

29. Bosak, J.; Kulich, C.; Rudman, L.; Kinahan, M., Be an advocate for others, unless you are a man: Backlash against gender-atypical male job candidates. Psychology of Men \& Masculinity 2018, 19 (1), 156-165.

30. Turban, S.; Freeman, L.; Waber, B., A study usd sensors to show that men and women are treated differently at work. Harvard Business Review 2017, 10.

31. Heilman, M. E.; Wallen, A. S.; Fuchs, D.; Tamkins, M. M., Penalties for success: Reactions to women who succeed at male gender-typed tasks. Journal for Applied Psychology 2004, 89 (3), 416-427.

32. Smith-Doerr, L.; Alegria, S.; Sacco, T., How diversity matters in the us science and engineering workforce: A critical review considering integration in teams, fields, and organizational contexts. Engaging Science, Technology and Society 2017, 3, 139-153.

33. Johnson, W. B.; Smith, D. G. How men can become better allies to women; 2018.

34. Nishii, L. H., The benefits of climate for inclusion for gender-diverse groups. Academy of Management Journal 2013, 50 (6), 1754-1774.

35. Bond, M. A.; Pyle, J. L., Diversity dilemmas at work. Journal of Management Inquiry 1998, 7 (3), 252-269.

36. Sturm, S., The architecture of inclusion: Advancing workplace equity in higher education. Harvard Journal of Law and Gender 2006, 29 (2; Summer 2006), 247-334.

37. Gilbert, J. A.; Ivancevich, J. M., Valuing diverity: A tale of two organziations. The Academy of Management Executive 2000, 14 (1), 93-105.

38. Stockard, J.; Green, J.; Lewis, P.; Richmond, G. L., Promoting gender equity in academic departments: A study of department heads in top-ranked chemistry departments. Journal of Women and Minorities in Science and Engineering 2008, 14, 1-27. 
39. Green, T. K.; Kalev, A., Discrimination-reducing measures at the relational level. Hastings Law Journal 2007, 59 (6), 1435-1462.

40. Dobbin, F.; Schrage, D.; Kalev, A., Resisting the iron cage: The effects of bureaucratic reforms to promote equity. SSRN 2014.

41. Hofmann, Y. E.; Strobel, M., Transparency goes a long way: Information transparency and its effect on job satisfaction and turnover intentions of the professoriate. Journal of Business Economics 2020, 90, 713-732.

42. Kidder, D. L.; Lankau, M.; Chrobot-Mason, D.; Mollica, K.; Friedman, R. A., Backlash toward diversity initiatives; examing the impact of diversity program justification, personal, and group outcomes. International Journal of Conflict Management 2004, 15 (1), 77-102.

43. Dobbin, F.; Kalev, A.; Kelly, E., Diversity management in corporate america. Contexts 2007, 6 (4), 21-27.

44. Kalev, A.; Dobbin, F.; Kelly, E., Best practices or best guesses? Assessing the efficacy of corporate affirmative action and diversity policies. American Sociological Review 2006, 71, 589-617.

45. Friedman, R. A.; Craig, K. M., Predicting joining and participating in minority employee network groups. Industrial Relations 2004, 43 (4), 793-816.

46. Ibarra, H., Race, opportunity, and diversity of social circles in managerial networks. The Academy of Management Journal 1995, 38 (3), 673-703.

47. Blake-Beard, S.; Bayne, M. L.; Crosby, F. J.; Muller, C. B., Matching by race and gender in mentoring relationships: Keeping our eyes on the prize. Journal of Social Issues 2011, 67 (3), 622-643.

48. Estrada, M.; Hernandez, P. R.; Schultz, P. W., A longitudinal study of how quality mentorship and resarch experience integrate underrepresented minorities into stem careers. CBE Life Sci Educ. 2017, Spring 17 (1), ar9.

49. Chapman, R. N., The thrive mosaic develomental framework: A systems activist approach to marginalized stem scholar success. American Behavioral Scientist 2018, 62 (5), 600-611.

50. Ensari, N. K.; Miller, N., The application of the personalization model in diversity management. Group Processes and Intergroup Relations 2006, 9 (4), 589-607.

51. Picciano, M. Why you need to upgrade your accountability system MMI Inc. [Online]. https://www.matrixmanagementinstitute.com/blog/why-you-need-upgrade-youraccountability-system/ (accessed March 5, 2021).

52. Whittington, K. B.; Smith-Doerr, L., Women inventors in context: Disparities in patenting across academia and industry. Gender and Society 2008, 22 (2), 194-218.

53. Nielsen, M. W.; Alegria, S.; Borjeson, L.; Etzkowitz, H.; Falk-Krzesinski, H. J.; Joshi, A.; Leahey, E.; Smith-Doerr, L.; Woolley, A. W.; Schiebinger, L., Gender diversity leads to better science PNAS 2017, 114 (8), 1740-1742.

54. Dom, F.; Ahmad, A., The importance of human capital managment in developing quality human capital. International Journal of Business and Economy 2020, 2 (1), 42-46.

55. Cameron, K. S.; Quinn, R. E., Diagnosing and changing organizational culture: Based on the competing values framework. Jossey-Bass: San Francisco, CA, 2011.

56. Allen-Ramdial, S. A.; Campbell, A. G., Reimagining the pipeline: Advancing stem diversity, persistence, and success. BioScience 2014, 64 (7), 612-618. 
57. Frehill, L. M.; Jeser-Cannavale, C.; Malley, J. E., Measureing outcomes: Intermediate indicators of institutional transformation, . University of Michigan Press: 2007; p 362.

58. Quinn, R. E., The positive organzation: Breaking free from coventioal cultures, constraints, and beliefs. Bberrett-Koehler Publishers, Inc.: 2015. 